\title{
In vivo Spectroscopy and Imaging of Nitroxide Probes
}

\author{
Valery V. Khramtsov
}

Additional information is available at the end of the chapter

http://dx.doi.org/10.5772/39129

\section{Introduction}

Magnetic resonance spectroscopic and imaging techniques are methods of choice for in vivo applications in animals and humans due to sufficient depth of microwave penetration in living tissues. Nuclear magnetic resonance, NMR, and its imaging modality, MRI, have found numerous biomedical and clinical applications but still suffer from limited functional resolution. Low intrinsic NMR sensitivity and overlap of the various endogenous NMR signals limit functional in vivo NMR and MRI applications beyond anatomical resolution. Electron paramagnetic resonance, EPR, has the advantage over NMR in functional specificity due to the absence of endogenous EPR signals but requires stable in vivo exogenous paramagnetic probes. Nitroxyl radicals, NRs, represent the most diverse class of stable organic radicals varying in stability, spectral properties and functionality which have been successfully used in numerous EPR spectroscopic and imaging applications. Synthesis of stable organic NRs (Lebedev \& Kayanovskii, 1959; Neiman et al., 1962), with an unpaired electron localized at a sterically protected NO group $\left(\rho_{0}^{\pi} \approx 0.6 ; \rho_{N}^{\pi} \approx 0.4\right)$, revolutionized numerous areas of EPR applications. Half a century of continuous progress in nitroxide chemistry has resulted in the design of specific NRs for spin labeling (Berliner, 1998), sitedirected spin labeling (Hubbell et al., 2000), EPR oximetry (Halpern et al., 1994; Swartz, 2004), pH (Khramtsov et al., 1982, 2005), thiols (Khramtsov et al., 1989, 1997), redox (Swartz et al., 2007) and NO measurements (Akaike et al., 1993; Joseph et al., 1993; Woldman et al., 1994). Over the past decade low-field L-band (1.2 GHz) EPR spectrometers and imagers have become commercially available allowing for functional EPR measurements in isolated organs (Komarov et al., 2012) and small animals such as mice (Kuppusamy et al., 2002; Bobko et al., 2012). Moreover, continuous waves (CW) EPR (Halpern et al., 1994; He et al., 2002) and pulsed EPR (Yasui et al., 2010) instruments with lower radio frequencies (RF) down to $250 \mathrm{MHz}$ have been constructed allowing for spectral-spatial functional imaging in 
larger animals, and potentially in humans. Recently, a functional proton-electron doubleresonance imaging (PEDRI) approach (Khramtsov et al., 2010; Efimova et al., 2011) based on MRI detection with EPR excitation of paramagnetic probes at pre-selected EPR fields/frequencies, has been developed. The latter approach inherits high resolution, fast image acquisition and the availability of anatomical information from MRI techniques. This chapter overviews the recent applications of nitroxide probes for functional spectroscopy and imaging of living tissues.

\section{Nitroxides as functional EPR probes}

\subsection{EPR-based oximetric applications of the nitroxides}

EPR oximetry is one of the most promising and rapidly developing techniques for measurement of oxygen in living tissues (Swartz, 2004). An advantage of EPR oximetry is that it is based on pure physical interaction, Heisenberg spin exchange, between paramagnetic molecules of probe and oxygen, and does not interfere with oxygen metabolism, therefore providing a basis for noninvasive oxygen measurements in biological systems. Initially, the paramagnetic probes for EPR oximetry were almost exclusively nitroxides (Backer et al., 1977; Lai et al., 1982; Froncisz et al., 1985; Bacic et al., 1989; Chan et al., 1989; Hyde \& Subszynski, 1989). Both the longitudinal (T1) and transverse $\left(\mathrm{T}_{2}\right)$ relaxation times of the NRs can be affected by collisions of the nitroxide with dissolved oxygen. The first observation of oxygen-induced NR broadening in various solvents was reported by Povich (Povich, 1975). Two years later the $T_{2}$ oximetry method was proposed and applied to follow mitochondrial respiration in samples containing about 100 liver cells (Backer et al., 1977). T1-sensitive EPR oximetry was developed by Hyde et al (Froncisz et al., 1985; Hyde et al., 1990). T2 oximetric applications using NRs are preferred for biological applications in low viscosity solutions because $\mathrm{T}_{2}$ is close to the collision rate resulting in optimal EPR sensitivity. On the other hand, $\mathrm{T}_{1}$ oximetry may have an advantage for applications in highly viscous environments and for nitroxide-labeled macromolecules due to the fact that the nitroxide $T_{1}>T_{2}$. $T_{1}$ oximetric methods include pulsed saturation-recovery, continuous wave saturation and rapid passage displays (Hyde \& Subszynski, 1989).

The typical effect of oxygen on the low-field component of the EPR spectrum of NRs is shown in Figure 1 for the five-membered ring pyrroline CTPO nitroxide. In the absence of oxygen each spectral component of the triplet spectrum shows additional superhyperfine splittings with 12 protons of four methyl groups and proton at carbon C-4 of the heterocycle. An increase in oxygen concentration results first in the broadening of the lines of the superhyperfine structure followed by the increase of the enveloped EPR linewidth, $\Delta \mathrm{H}_{\mathrm{pp}}$.

Note that most six- and five-membered ring NRs with larger numbers of protons in the radical heterocycle do not reveal superhyperfine structure even in the absence of oxygen, 


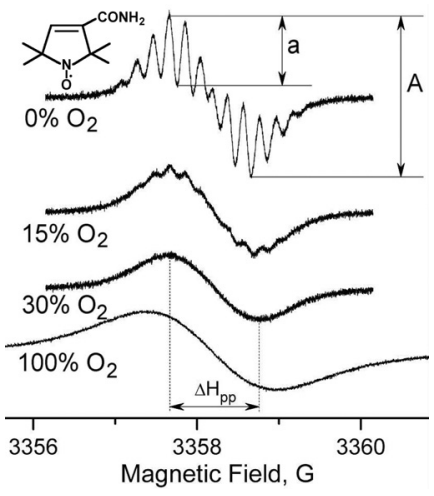

Figure 1. Chemical structure of the CTPO nitroxide and the EPR spectra of its low-field spectral component measured in aqueous solutions at various oxygen concentrations at $37^{\circ} \mathrm{C}$.

e.g. TEMPO radical of the piperidine type (see Fig. 2). The oxygen-induced line-broadening effects vary slightly with the NR structure and are about $\Delta \mathrm{H}_{\mathrm{pp}} / \Delta\left[\mathrm{O}_{2}\right] \approx 500 \mathrm{mG} / 100 \%$ oxygen or $450 \mathrm{mG} / \mathrm{mM}$ of oxygen (see Fig. 1 and 2).

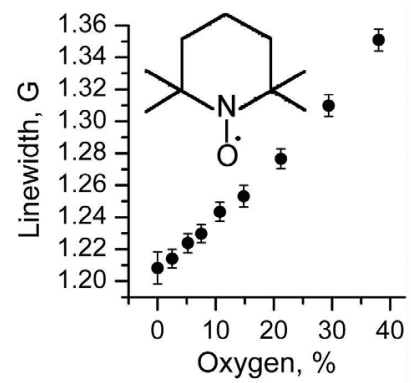

Figure 2. Chemical structure of TEMPO NR and oxygen-induced broadening of its low-field spectral line measured at $24^{\circ} \mathrm{C}$. Linewidth at $100 \%$ oxygen is equal to $1.70 \mathrm{G}$ (not shown).

The well-developed chemistry of the NRs (Volodarsky et al., 1994; Hideg et al., 2005; Karoui et al., 2010) allows manipulation of their structure and properties, including charge, presence of hydrophilic or hydrophobic groups, and ability to be targeted. Small neutral NRs normally easily penetrate cellular membranes and are equally distributed throughout the intracellular and extracellular environments. Conversely, charged NRs will not cross the plasma membrane and thus can be used to measure oxygen concentrations in the extracellular compartment (Glockner et al., 1993; Baker et al., 1997). NRs encapsulated in liposomes or linked to carrier molecules can be used to achieve organ or tissue selectivity (Gallez et al., 1993). In general, NRs have low toxicity and can be administered to an animal by infusion or by intraperitoneal, intravenous or intratissue injection. To protect NRs against reduction and enhance their oxygen sensitivity Liu et al. (Liu et al., 1994) encapsulated NRs in proteinaceous microspheres filled with an organic liquid. The authors used encapsulated NR to measure the changes in oxygen 
concentration in vivo for $70 \mathrm{~min}$ after intravenous injection of the microspheres into a mouse. Potential concern of this approach is the leakage, as well as release of the organic liquid from the microspheres when they are eventually metabolized, resulting in possible toxicity to the tissue.

Figure 3 demonstrates an example of the L-band EPR oximetry application using TEMPO nitroxide (see Fig.2 for the structure) for monitoring ischemia-induced oxygen depletion in isolated rat hearts (Zweier \& Kuppusamy, 1988; Kuppusamy et al., 1994). The spectra showed a gradual decrease in the linewidth over the duration of ischemia approaching the linewidth observed in the absence of oxygen. Oxygen consumption observed in cardiopleged hearts subjected to global ischemia (Kuppusamy et al., 1994) was significantly slower than in noncardiopleged hearts (Zweier \& Kuppusamy, 1988). This would be expected since contractile function of cardiopleged hearts is arrested. The oxygen consumption data for cardiopleged heart were obtained from spectral-spatial EPRI which allowed for spatially resolved oxygen mapping but required long acquisition times (16 min in Fig. 3a). PEDRI provides a faster alternative for oxygen mapping. Application of PEDRI for myocardium oxygen mapping was first demonstrated in perfused sheep heart using a high concentration, 4 mM, of Fremy's salt nitroxide (Grucker \& Chambron, 1993).
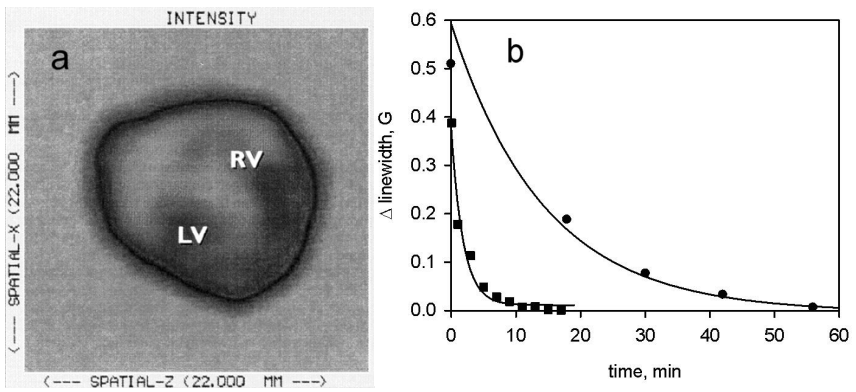

Figure 3. (a). Cross-sectional transverse 2D-spatial L-band EPR image of the isolated rat heart preloaded with $1 \mathrm{mM}$ TEMPO (field of view, $22 \times 22 \mathrm{~mm}^{2}$; acquisition time, $16 \mathrm{~min}$ ). The structure of the left ventricle (LV) and right ventricle (RV) are observed. (b). Changes in L-band EPR linewidth of TEMPO spin label induced by oxygen depletion during ischemia in cardiopleged $(\bullet)$ and noncardiopleged ( $\bullet$ ) hearts. Adapted from (Zweier \& Kuppusamy, 1988; Kuppusamy et al., 1994), copyright National Academy of Sciences, U.S.A.

Low sensitivity of the NRs to oxygen tensions below $40 \mathrm{mmHg}$ and concentration-induced line broadening complicate quantitative oximetric applications of the NRs. Typically, the self-broadening effect is about $100-200 \mathrm{mG} / \mathrm{mM}$ of NRs, and may interfere with accurate oxygen measurements at NR concentrations above $100 \mu \mathrm{M}$. Application of deuterated NRs provides significant enhancement in sensitivity to low oxygen concentrations due to the narrowing linewidth, $\Delta \mathrm{H}_{\mathrm{pp}}$ (Kuppusamy et al., 1994; Gallez et al., 1996a; Velan et al., 2000). Alternatively, measurement of "the depth of resolution" of the NRs superhyperfine structure (e.g. parameter a/A for the CTPO shown in the Fig.1) provides similar or even better sensitivity to oxygen than perdeuterated NRs, and has been used for oxygen 
measurements in cellular and enzymatic systems (Backer et al., 1977; Sarna et al., 1980; Lai et al., 1982). However, both approaches still suffer from concentration-induced line broadening which is difficult to disentangle from oxygen-induced broadening. To overcome this problem, Halpern et al. proposed selectively deuterated nitroxide with only one hydrogen hyperfine splitting, mHCTPO (see Scheme 1) (Halpern et al., 1994). Increasing NR concentration but not oxygen results in narrowing of hydrogen hyperfine splitting. This allows for discrimination between oxygen- and concentration-induced line broadening, and therefore, for quantitative oxygen detection in living tissues with sensitivity about 10 mmHg. The authors demonstrated an efficiency of low-field $250 \mathrm{MHz}$ EPR oximetry in combination with a mHCTPO probe to report oxygen concentration in murine FSa and NFSa fibrosarcomas $7 \mathrm{~cm}$ deep in tissues of a living animal. An oximetric 2D (1spectral/1 spatial) spectral image of the tumor was also obtained allowing, in principle, direct assessment of tumor hypoxia to determine the usefulness of radiation and chemotherapy adjuvants directed to hypoxic cell compartments. In another application, cell-permeable perdeuterated NR, PDT (see Scheme 1), was applied to measure oxygenation level in radiation-induced fibrosarcoma (RIF-1) in mice (Kuppusamy et al., 1998). The data showed a 3 -fold lower level of oxygenation of the tumor tissue compared with that of the normal muscle.

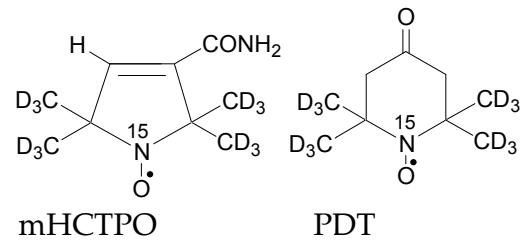

Scheme 1. Chemical structures of the NRs referred to in the text: 4-protio-3-carbamoyl-2,2,5,5tetraperdeuteromethyl-3-pyrrolinyl-1-15N-oxy (mHCTPO) and 4-oxo-2,2,6,6-tetramethylpiperidine-d 16 $1-15$-oxyl (perdeuterated tempone, PDT).

Distribution of the NRs in living tissue can be measured using EPRI techniques as demonstrated in Fig. 3a. Moreover, spectral-spatial imaging can be performed which contains a complete spectral profile, as a function of field, at each spatial voxel element. Because the spatial and spectral dimensions are fully separable, information about local linewidth, and hence local oxygen concentration, can be derived independently from local spin density (Velan et al., 2000; Kuppusamy \& Zweier, 2004). To date most NRs imaging applications have been performed using CW EPRI. Nitroxide imaging by time-domain pulsed EPR had not been attempted until recently because of the short spin-spin relaxation times, typically under 1 microsecond. Nevertheles, recent advances in RF electronics have enabled the pulses on the order of 10-50 ns (Murugesan et al., 1997) and improved spectrometer recovery times, therefore providing an opportunity for in vivo pulsed EPR imaging of the nitroxides. Figure 4 shows oxygen mapping of a tumor-bearing anesthetized mouse obtained by pulsed EPRI using PDT nitroxide (Scheme 1) (Hyodo et al., 2009). Strong heterogeneity of tumor oxygenation and significant hypoxic regions $(<10 \mathrm{mmHg})$ 
characteristic of tumor pathogenesis were observed demonstrating the capability of in vivo functional nitroxide imaging using time-domain pulsed EPR.

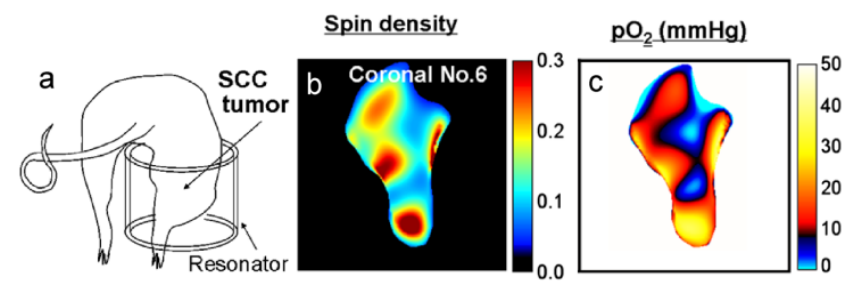

Figure 4. 3D-pulsed EPR imaging of tumor oxygenation using PDT nitroxide. (a) Schematic illustration of tumor-implanted mouse setting in the smaller parallel coil resonator. (b) Coronal slice views selected from 3D-spin density map of the nitroxide in tumor bearing leg, and (c) corresponding oxygen image calculated from line width distribution of PDT. Adapted from (Hyodo et al., 2009), copyright 2009, Elsevier Inc.

EPR applications of other oxygen-sensitive paramagnetic materials include soluble trityl radicals (Krishna et al., 2002; Bobko et al., 2009) and particulate probes such as lithium phthalocyanine particles (Liu et al., 1993; Presley et al., 2006) and carbonaceous materials (chars, coals, carbon blacks) (Clarkson et al., 1998). It should be noted that particulate probes such as lithium phthalocyanine and synthetic char are suitable for measurements of oxygen partial pressure in place of implantation whereas soluble probes such as nitroxides and trityl compounds more suitable for imaging experiments.

\subsection{In vivo evaluation of redox state using nitroxide probes}

Regulation of tissue redox status is important for maintenance of normal physiological conditions in the living body. Disruption of redox homoeostasis may lead to oxidative stress and can induce many pathological conditions such as cancer, neurological disorders and ageing. The intracellular thiols, and particularly the redox couple of glutathione, GSH, and its disulfide form, GSSG, are considered the major regulators of the intracellular redox state (Schafer \& Buettner, 2001). Therefore, noninvasive spectroscopic evaluation and imaging of tissue redox status and, in particularly, GSH redox status, could have clinical applications (Kuppusamy \& Krishna, 2002; He et al., 2004; Swartz et al., 2007; Hyodo et al., 2008; Ojha et al., 2008; Roshchupkina et al., 2008; Bobko et al., 2012).

\subsubsection{Nitroxides as redox-sensitive paramagnetic probes}

NRs introduced into biologically relevant systems are predominantly observed in the radical and hydroxylamine forms and exist in redox equilibrium as shown in Scheme 2. The reduction of NRs to EPR-silent hydroxylamines in many cases is an unfavorable factor that limits their applications. On the other hand, the EPR-measured rates of NR reduction depend on overall tissue redox status allowing for the differentiation of normal and pathological states (Kuppusamy et al., 2002; Ojha et al., 2008; Bobko et al., 2012). The reduction of cell-permeable 
NRs to hydroxylamines is primarily intracellular and, therefore to a great extent is determined by intracellular redox status. On the other hand, cell-impermeable nitroxides allow for detection of reducing capacity of extracellular microenvironment.
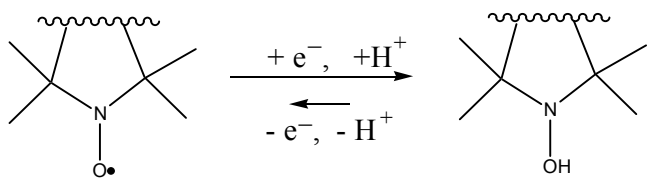

Scheme 2. Illustration of the nitroxide/hydroxylamine redox couple. In general, for most biologically relevant samples one-electron reduction of the nitroxides prevails and the equilibrium is strongly shifted towards the hydroxylamine (Kocherginsky \& Swartz, 1995).

Cancer and ischemic heart disease, two leading causes of mortality in the United States, represent pathologic conditions with compromised redox state. Figure 5 demonstrates the application of cell-permeable CP nitroxide (see Scheme 3) for EPR in vivo assessment of myocardial tissue redox status in a mouse model of regional ischemia (Zhu et al., 2007). Authors observed about two-fold ischemia-induced increase of the overall myocardial reducing capacity in the area at risk. Conversely, the $\mathrm{CP}$ reduction rates in reperfused hearts were about $30 \%$ lower than in pre-ischemic hearts. The latter correlated with oxygen overshoot in post-ischemic hearts. Both lower redox potential and higher oxygen may result in elevated production of reactive oxygen species and myocardial damage. Authors observed that ischemic preconditioning normalizes post-ischemic myocardial oxygenation and tissue redox status which may contribute to the mechanisms of myocardial protection.
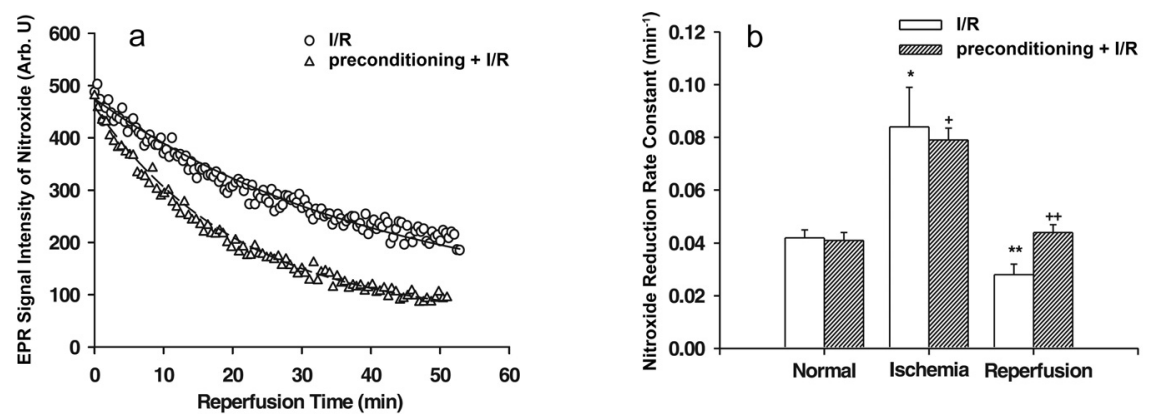

Figure 5. (a). In vivo EPR measurements of myocardial tissue redox status in a mouse model of $30 \mathrm{~min}$ regional ischemia and $60 \mathrm{~min}$ reperfusion (I/R). $5 \mu \mathrm{l}$ of a $10 \mathrm{mM}$ solution of $\mathrm{CP}$ probe was injected in the area at risk. EPR signal intensity decays are shown for the control $(\circ)$ and preconditioned $(\Delta)$ groups measured during reperfusion. (b) Reduction rate constants of the CP nitroxide before, during, and after ischemia in control I/R and preconditioned I/R mice. Adapted from (Zhu et al., 2007), copyright 2007, the American Physiological Society.

Tumor cells are known to generate significant alterations in the redox status. This status is an important determinant in the response of the tumor to certain chemotherapeutic agents, radiation, and bioreductive hypoxic cell cytotoxins (Cook et al., 2004). Figure 6 illustrates the application of cell-impermeable RSG nitroxide (see Scheme 3) designed to access both 

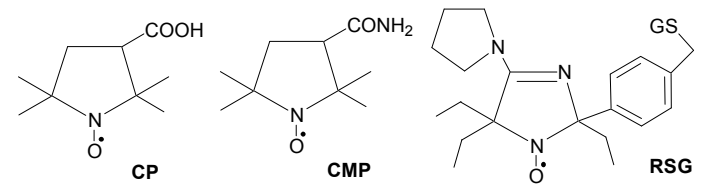

Scheme 3. Representative structures of the NRs used for in vivo evaluation of tissue redox status, cellpermeable pyrrolidine NRs, CP and CMP, and cell-impermeable imidazoline nitroxide, RSG, bound to hydrophilic tripeptide, glutathione (GSH).
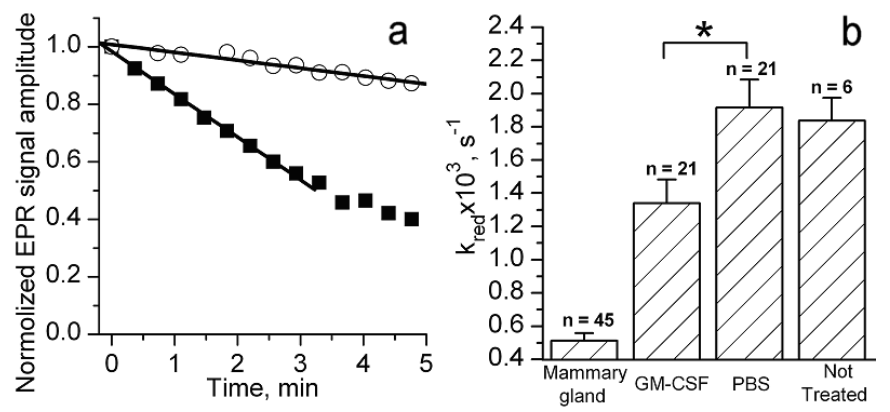

Figure 6. (a) EPR signal decay of the NR probe RSG measured in vivo after probe injection $(10 \mu \mathrm{L}, 10$ $\mathrm{mM}$ ) in mammary gland (o) and mammary tumor (-) of PyMT mouse. (b) The reduction rates of RSG nitroxide, kred, in extracellular media of normal mammary glands and variously-treated tumors (GMCSF: Granulocyte Macrophage Colony-Stimulating Factor; ${ }^{*} p<0.02$ ). From ref. (Bobko et al., 2012) with permission from John Wiley \& Sons, Ltd.

extracellular tumor redox and $\mathrm{pH}$ (Bobko et al., 2012), latter measurements being discussed in the Section 2.3. The extracellular reducing capacity of tumor tissue was found to be about four-fold higher compared with that of the normal mammary gland (Fig. 6). Inhibition of tumor angiogenesis with granulocyte-macrophage colony-stimulating factor (GM-CSF) resulted in significant "normalization" of the tumor redox status (Fig. 6b) as well as correlating with a decrease in tumor growth and metastases (Eubank et al., 2009).

EPR studies using cell-permeable nitroxides support significantly higher reducing capacity of the tumor tissues. Figure 7 demonstrates L-band EPRI application for redox mapping of the tumor in living mice (Kuppusamy \& Krishna, 2002; Kuppusamy et al., 2002) using CMP nitroxide. A significant decrease in CMP reduction rates after treatment with a GSH depleting agent clearly demonstrates a central role of GSH in tissue redox homeostasis. Note that in general, appreciable chemical reduction of the NRs by GSH is not observed (Finkelstein et al., 1984; Glebska et al., 2003; Bobko et al., 2007b). However GSH significantly contributes to the reduction of the NRs indirectly by acting as a secondary source of reducing equivalents (Takeshita et al., 1999; Kuppusamy et al., 2002; Bobko et al., 2007b).

Application of the NRs as redox-sensitive contrast agent for EPRI, MRI and PEDRI (also termed as Overhauser magnetic resonance imaging, OMRI) was recently discussed (Hyodo et al., 2008). In summary, NRs provide a useful tool for quantitative assessment and mapping of the redox environment in living tissues. 

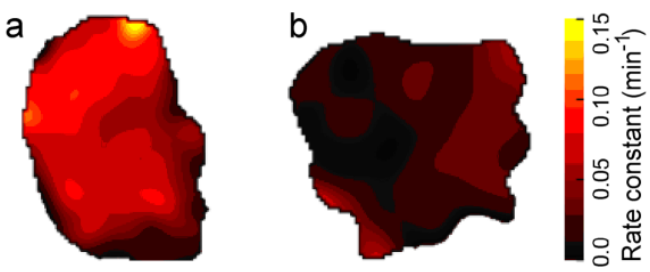

Figure 7. Redox mapping of untreated (a) and BSO-treated (b) mice tumors. 2-D spatial map of pseudofirst order rate constants of the CMP reduction in RIF-1 tumor implanted in the upper leg of a mouse was obtained using in vivo L-band EPRI. The rate of reduction was significantly slower in tumor of mouse treated for 6 hours with $2.25 \mathrm{mmol} / \mathrm{kg}$ of L-buthionine-S,R-sulfoximine (BSO), a GSH depleting agent. Adapted from (Kuppusamy et al., 2002), copyright 2002, American Association for Cancer Research.

\subsubsection{Nitroxides as glutathione-sensitive paramagnetic probes}

The redox couple of glutathione, GSH, and its disulfide form, GSSG, is considered the major regulator of the intracellular redox state (Schafer \& Buettner, 2001). Therefore, GSH redox status in vivo might be a useful indicator of disease risk in humans. The use of fluorometric, photometric, and chromatographic assays for GSH measurements is mostly limited to in vitro or ex vivo systems due to the invasiveness involved and the limited depth of penetration of light (Ellman, 1959; Tietze, 1969; Yamashita \& Rabenstein, 1989; Patsoukis \& Georgiou, 2005). NMR based approaches normally detect endogenous GSH but have somewhat low sensitivity and the spectral assignment is complicated due to the overlapping of numerous resonances (Livesey et al., 1992; Willis \& Schleich, 1995; Terpstra et al., 2003; Potapenko et al., 2005).

EPR spectroscopy in combination with thiol-specific nitroxides allows for determination of the accessible thiol groups in various biological macromolecules, such as human plasma low-density lipoproteins (Kveder et al., 2003) and erythrocyte membranes (Soszynski \& Bartosz, 1997). This approach normally requires purification of the sample from the unbound label and can not be used in vivo. Moreover, application of thiol-specific mononitroxides for EPR measurement of glutathione or cysteine is hardly possible due to insignificant EPR spectral changes of the label upon binding to low-molecular-weight compounds. The latter limitation was overcome by the development of paramagnetic analogs of Ellman's reagent, namely disulfide nitroxyl biradicals, RSSR, shown in Scheme 4 (Khramtsov et al., 1989; 1997; Roshchupkina et al., 2008).

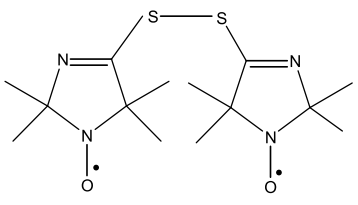

$\mathrm{R}_{1} \mathrm{SSR}_{1}$

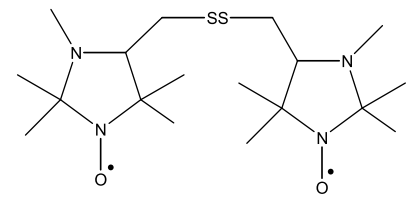

$\mathrm{R}_{2} \mathrm{SSR}_{2}$

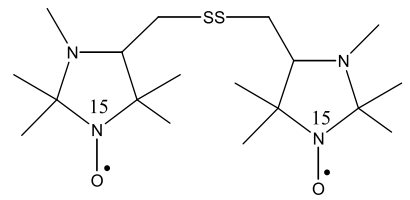

${ }^{15} \mathrm{~N}-\mathrm{R}_{2} \mathrm{SSR}_{2}$

Scheme 4. Structures of the disulfide nitroxyl biradicals, $\mathrm{R}_{1} \mathrm{SSR}_{1}, \mathrm{R}_{2} \mathrm{SSR}_{2}$ and ${ }^{15} \mathrm{~N}-\mathrm{R}_{2} \mathrm{SSR}_{2}$. 
EPR spectra of the RSSR labels are significantly affected by intra-molecular spin exchange between two radical fragments resulting in appearance of "biradical" spectral components in addition to the conventional triplet spectral pattern of the mononitroxide. Figure 8a demonstrates the typical changes of the EPR spectra of $\mathrm{R}_{2} \mathrm{SSR}_{2}$ upon GSH addition consistent with splitting of the biradical disulfide bond and formation of two monoradicals due to the reaction of thiol-disulfide exchange, RSSR + GSH $\rightarrow$ RSSG + RSH. Figure 8b shows the corresponding kinetics of the monoradical component increase allowing for the calculation of the rate constant. The RSSR labels being lipophilic compounds diffuse easily across cellular membranes where they reacts with intracellular GSH providing a reliable EPR approach for determination of GSH in vitro (Weiner, 1995) and in vivo (Roshchupkina et al., 2008; Bobko et al., 2012). The approach is based on a dominant contribution of the GSH in the intracellular pool of fast-reacting thiols.
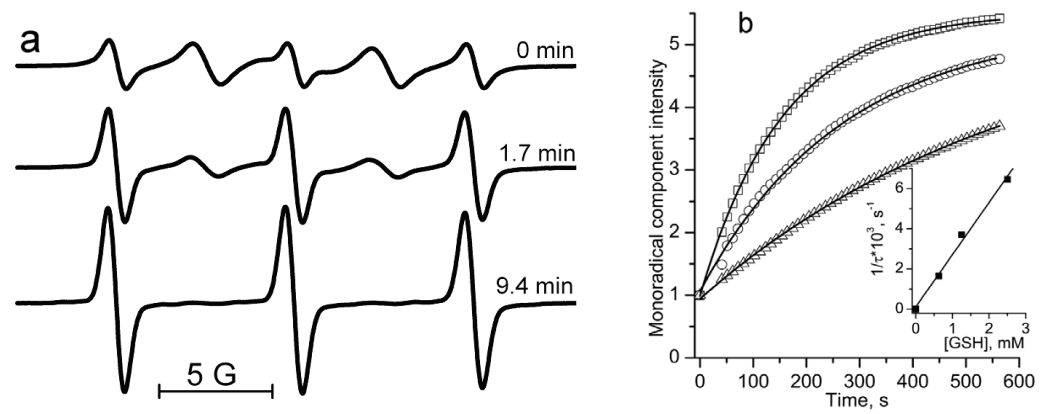

Figure 8. (a). The EPR spectra of $100 \mu \mathrm{M} \mathrm{R}_{2} \mathrm{SSR}_{2}$ measured at various time points after incubation with $2.5 \mathrm{mM}$ GSH in $0.1 \mathrm{M} \mathrm{Na}$-phosphate buffer, $\mathrm{pH} \mathrm{7.2,} \mathrm{at} 34^{\circ} \mathrm{C}$. (b). The kinetics of the increase of amplitude of low-field monoradical component of the EPR spectrum after addition of GSH: $0.625 \mathrm{mM}$ $(\Delta), 1.25 \mathrm{mM}(\circ)$ and $2.5 \mathrm{mM}(\square)$. Lines represent the best fit of the experimental kinetics to the monoexponents. Insert: the dependence of inverse time constant of the exponential kinetics, $1 / \tau$, on [GSH]. The linear regression $\left(1 / \tau=\mathrm{k}_{\mathrm{obs}} \times[\mathrm{GSH}]\right)$ provides the observed rate constant value of the reaction between GSH and $\mathrm{R}_{2} \mathrm{SSR}_{2}$, $\mathrm{k}_{\mathrm{obs}}\left(\mathrm{pH} 7.2,34^{\circ} \mathrm{C}\right)=2.8 \pm 0.2 \mathrm{M}^{-1} \mathrm{~s}^{-1}$. From the ref. (Bobko et al., 2012) with permission from John Wiley \& Sons, Ltd.

The convenient time window of the reaction of the imidazolidine RSSR labels, $\mathrm{R}_{2} \mathrm{SSR}_{2}$ (Khramtsov et al., 1997) and ${ }^{15} \mathrm{~N}-\mathrm{R}_{2} \mathrm{SSR}_{2}$ (Roshchupkina et al., 2008) allows for quantitative measurement of GSH content by the analysis of their EPR spectral change kinetics. The kinetics approach looses the attractive simplicity of the static EPR measurements performed in vitro using fast-reacting $\mathrm{R}_{1} \mathrm{SSR}_{1}$ label but gains a decisive advantage by using low concentrations of the label compared to the GSH content. This important advantage makes the approach less invasive and, therefore, applicable in vivo. Recently we demonstrated their applicability for in vivo GSH detection in ovarian tumor allograft (Roshchupkina et al., 2008) and breast cancer tumors (Bobko et al., 2012) in mice using L-band EPR spectroscopy.

Figure 9a shows typical in vivo L-band EPR spectra measured immediately after $\mathrm{R}_{2} \mathrm{SSR}_{2}$ probe intratumoral injection and $150 \mathrm{~s}$ after injection at the time point of maximal monoradical signal amplitude. Comparison of the integral intensities of the spectra shows less than $10 \%$ loss of 

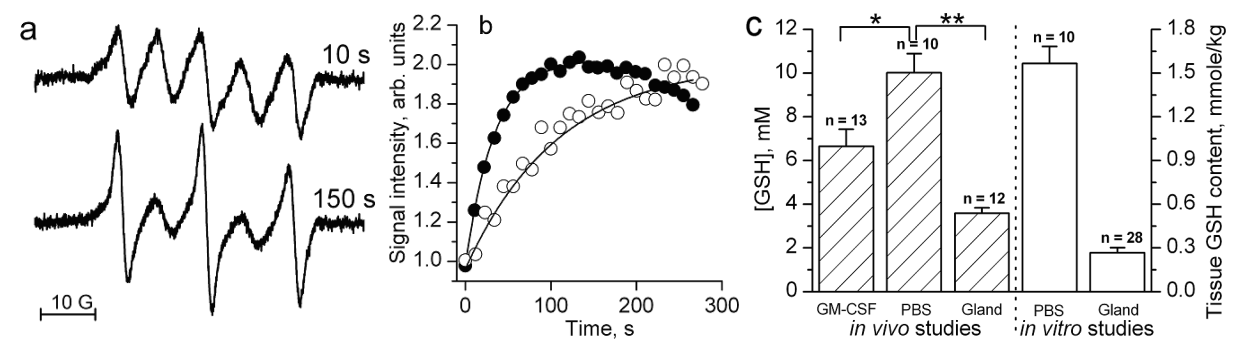

Figure 9. (a) L-band EPR spectra of the $\mathrm{R}_{2} \mathrm{SSR}_{2}$ probe measured in vivo in mammary tumor of female FVB/N mice $10 \mathrm{~s}$ and $150 \mathrm{~s}$ after probe injection. (b) Kinetics of the monoradical peak intensity change measured in tumor $(\bullet)$ and normal mammary gland (o). The solid lines are the fits of the initial part of the kinetics by the monoexponent $I_{m}(t)=I_{m}^{\max }-\left(I_{m}^{\max }-I_{m}^{t=0}\right) \exp \left(-k_{o b s}[G S H] \cdot t\right)$ supposing $\mathrm{kobs}_{\mathrm{s}}=2.8 \mathrm{M}^{-1} \mathrm{~s}^{-1}$ (see Fig. 8 b) and yielding [GSH] $=10.7 \mathrm{mM}$ and $3.3 \mathrm{mM}$ for the tumor and mammary gland, correspondingly. (c) Intracellular [GSH] measured using $\mathrm{R}_{2} \mathrm{SSR}_{2}$ probe in vivo, and tissue GSH contents measured in vitro in normal mammary glands and mammary tumors of female FVB/ $\mathrm{N}$ mice $\left({ }^{*} \mathrm{p}<0.01\right.$, ${ }^{* *} \mathrm{p}<0.002$ ). From (Bobko et al., 2012) with permission from John Wiley \& Sons, Ltd.

the total EPR signal, supporting an insignificant contribution of the reduction and justifying approximation of the initial exponential signal increase by the reaction of $\mathrm{R}_{2} \mathrm{SSR}_{2}$ with GSH. Figure $9 \mathrm{~b}$ shows the typical kinetics of the monoradical spectral peak intensity change measured in mammary tumor and normal mammary gland of female FVB/N mice. The analysis of the kinetics calculates the GSH concentration to be three-fold higher in tumor compared with that in mammary gland. Figure 9c compares GSH contents measured in vivo with those measured in tissue homogenates from the sacrificed animals. While quantitative comparison of in vitro and in vivo data is difficult and requires knowledge of the relative intracellular aqueous volume of the total tissue volume (Vaupel, 2009), qualitatively in vitro measurements confirm significantly higher GSH levels in tumors. The observed decrease of intracellular GSH measured in vivo upon treatment with GM-CSF correlates with decrease of extracellular reducing capacity (cf. figs. $6 \mathrm{~b}$ and 9c) therefore supporting interrelationship between extracellular and intracellular tumor redox states.

Intracellular GSH has been shown to be one of the major factors modulating tumor response to a variety of commonly used anti-neoplastic agents, such as cisplatin (Rabik \& Dolan, 2007). The ${ }^{15} \mathrm{~N}-\mathrm{R}_{2} \mathrm{SSR}_{2}$ probe has been used to compare in vivo concentrations of GSH in cisplatin-resistant and cisplatin-sensitive tumors in ovarian tumor-bearing mice (Roshchupkina et al., 2008). The use of ${ }^{15} \mathrm{~N}$-substituted probe resulted in decreasing the number of EPR spectral lines and about a two-fold increase in the signal-to-noise ratio compared with nonsubstituted $\mathrm{R}_{2} \mathrm{SSR}_{2}$ label which is important for in vivo applications. The obtained two-fold higher levels of GSH in cysplatin-resistant tumors are in agreement with previously reported data (Lee et al., 1989). GSH depletion was supposed to re-sensitize drug-resistant ovarian cancer cells to cisplatin. Figure 10 shows EPR imaging of the $\mathrm{R}_{2} \mathrm{SSR}_{2}$ probe in cisplatin-resistant ovarian xenograft tumors confirming a significantly lower reducing capacity of the tumors in NCX-4040-treated mice compared with untreated animals, apparently due to GSH depletion by NCX-4040 drug (Bratasz et al., 2008). 


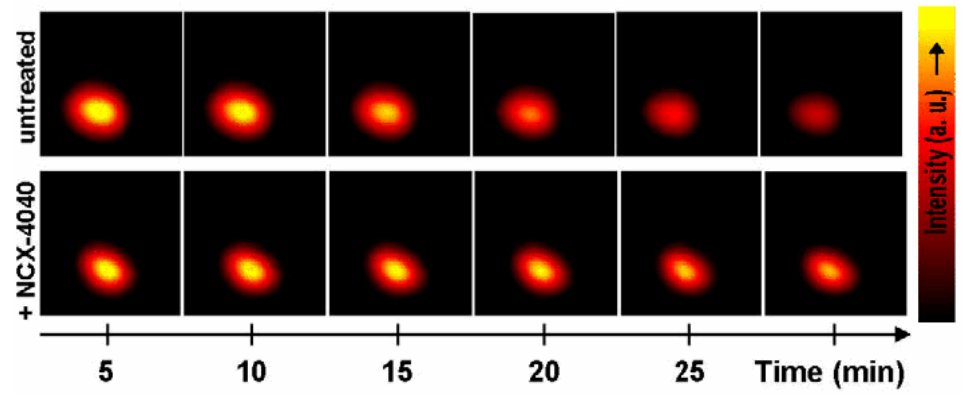

Figure 10. In vivo L-band EPR redox images of cisplatin-resistant ovarian xenograft tumors in mice obtained after intrarumoral injection of $\mathrm{R}_{2} \mathrm{SSR}_{2}$ probe. The images show the probe distribution in the tumor, while the tumor itself is not visible. Tumor treated with a NCX-4040 drug shows a significantly lower capacity to reduce the $\mathrm{R}_{2} \mathrm{SSR}_{2}$ probe when compared with untreated tumors. Adapted from (Bratasz et al., 2008) with permission.

As can be concluded from figures $9 \mathrm{~b}$ and 10, the EPR signal changes of the $\mathrm{R}_{2} \mathrm{SSR}_{2}$ probe show biphasic character: (i) comparatively fast monoradical signal increase due to the reaction with GSH, and (ii) slow signal decay due to bioreduction. A comparatively long EPRI acquisition time of about $5 \mathrm{~min}$ did not allow us to resolve the first phase of the kinetics from images given in Figure 10. With the development of faster imaging techniques, e.g. functional PEDRI discussed in the section 2.3.3, paramagnetic disulfide RSSR nitroxides can be used as dual function intracellular GSH and redox imaging probes.

In summary, it seems likely that EPR and EPR-based imaging approaches to visualize redox processes in living tissues, and in particular to assess intracellular GSH, will become increasingly utilized and valuable tools.

\subsection{In vivo spectroscopy and imaging of $\mathrm{pH}$ using nitroxide probes}

Spatially and temporarily addressed $\mathrm{pH}$ measurements in vivo are of considerable clinical relevance due to the critical role $\mathrm{pH}$ status plays in physiology and pathophysiology of living organisms. In vivo $\mathrm{pH}$ assessment using ${ }^{31} \mathrm{P}-\mathrm{NMR}$ and inorganic phosphate, $\mathrm{P}_{\mathrm{i}}$, suffers from low intrinsic NMR sensitivity and lack of functional resolution (about 0.2-0.3 pH units) (Gillies et al., 1982; Pietri et al., 2001). It is assumed that the chemical shift of endogenous $P_{i}$ reflects intracellular $\mathrm{pH}$ because of the generally higher fraction of intracellular volume, and 2-3-fold higher intracellular Pi concentrations over extracellular ones (2-3 mM and ca. $1 \mathrm{mM}$, respectively). Because of these problems, exogenous $\mathrm{pH}$ probes are being designed for NMR spectroscopy to improve detection of myocardial acidosis (Pietri et al., 2001) and extracellular pH in tumors (Gillies et al., 1994; 2004). Upon application of exogenous probes, low-field EPR spectroscopy has higher sensitivity compared with NMR for the same probe concentration, and reasonable depth of penetration in living tissues. 


\subsection{1. $p H$ effect on the EPR spectra of stable nitroxides}

The first $\mathrm{pH}$ effect on EPR spectra of stable NRs was observed in strong acids and was related to protonation of the nitroxyl fragment itself (Hoffman \& Eames, 1969; Malatesta \& Ingold, 1973). Imino nitroxyl radicals (Ullman \& Osiecki, 1970) were apparently the first reported stable NRs with spectral sensitivity in physiological range but did not find applications as $\mathrm{pH}$ probes due to the complexity of their EPR spectra and rapid reduction to EPR silent products in biological fluids (Woldman et al., 1994; Haseloff et al., 1997; Bobko et al., 2004). The observed $\mathrm{pH}$ effects on the NRs of piperidine and pyrrolidine types with ionizable functional groups were impractically small (Hsia \& Boggs, 1972; Quintanilha \& Mehlhorn, 1978; Nakaie et al., 1981; Mathew \& Dodd, 1985; Khramtsov \& Weiner, 1988; Saracino et al., 2002) due to the long distance between radical center and ionizable group.

Stable imidazoline and imidazolidine NRs have been proven to be the most useful spin probes for EPR spectroscopy and imaging of $\mathrm{pH}$ (Khramtsov et al., 2000, Khramtsov, 2005) due to the large effect of $\mathrm{pH}$ on their EPR spectra and large number of structures synthesized. Scheme 5 illustrates the chemical origin of the $\mathrm{pH}$ effect on EPR spectra of these types of NR. Protonation results in an EPR-detected difference in hyperfine splitting, an, and g-factor ( $\Delta \mathrm{a} \approx 1 \mathrm{G}$ and $\Delta \mathrm{g} \approx 0.0002$ ) between $\mathrm{R}$ and $\mathrm{RH}^{+}$forms (Khramtsov et al., 1982). For NR with an equilibrium constant $K_{a}$, the ratio of concentrations of these two forms is described by the Henderson-Hasselbalch equation, $\left[\mathrm{H}^{+}\right]=K_{a}\left[\mathrm{RH}^{+}\right] /[\mathrm{R}]$, providing the basis for EPR measurements of $\mathrm{pH}$. One of the great strengths of the technique is that it is ratiometric, the $\mathrm{pH}$ measurement being independent of the NR concentration but dependent on the ratio, $\left[\mathrm{RH}^{+}\right] /[\mathrm{R}]$. In general, spectral simulation is required for accurate $\left[\mathrm{RH}^{+}\right] /[\mathrm{R}]$ determination. In practice, two convenient spectral parameters can be used as $\mathrm{pH}$ markers: (i) the ratio of peak intensities of $\mathrm{RH}^{+}$and $\mathrm{R}$ spectral components resolved upon detection by high-frequency EPR and partly resolved in X-band EPR (9.5 GHz) spectra, and (ii) nitrogen hyperfine splitting, aN, measured as a distance between unresolved spectral components, and being used almost exclusively as a highly sensitive $\mathrm{pH}$ marker in numerous applications. Note that sensitivity of the hyperfine splitting to $\mathrm{pH}$ values depends both on EPR frequency and spectrometer settings (e.g., modulation amplitude) and can be optimized (Khramtsov et al., 2004).
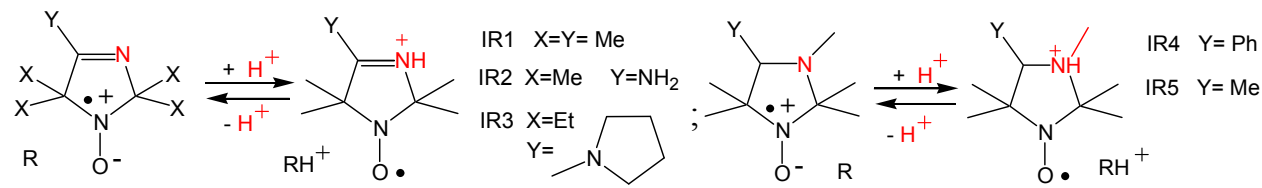

Scheme 5. Reversible protonation of the nitrogen atom N-3 of the imidazoline and imidazolidine NRs, and chemical structures of the IR1-IR5 referred in the Figure 11. Two main resonance structures are shown illustrating higher unpaired electron density on nitrogen atom $\mathrm{N}-1$ in the unprotonated form.

Up to the present a wide variety of $\mathrm{pH}$-sensitive NRs have been developed with different ranges of $\mathrm{pH}$ sensitivity, labeling groups, lipophilicity and stability towards bioreduction (Khramtsov \& Weiner, 1988; Khramtsov \& Volodarsky, 1998; Kirilyuk et al., 2004; 2005; Voinov et al., 2005; Bobko et al., 2012). These spin pH probes, together with low-field EPR- 
based techniques, offer unique opportunities for non-invasive $\mathrm{pH}$ assessments in living animals in compartments with widely varying $\mathrm{pH}$ ranges. Figure 11 exemplifies a set of nitroxide $\mathrm{pH}$ probes that cover all $\mathrm{pH}$ ranges from acidic values observed in stomach and ischemic tissues to alkaline values characteristic of mitochondria. The potential applications are enormous, as tumors and ischemic areas may have acidic $\mathrm{pH}$ values compared to surrounding tissues, local areas of infection or inflammation can exhibit specific localized $\mathrm{pH}$ reductions allowing infection to be imaged and localized.

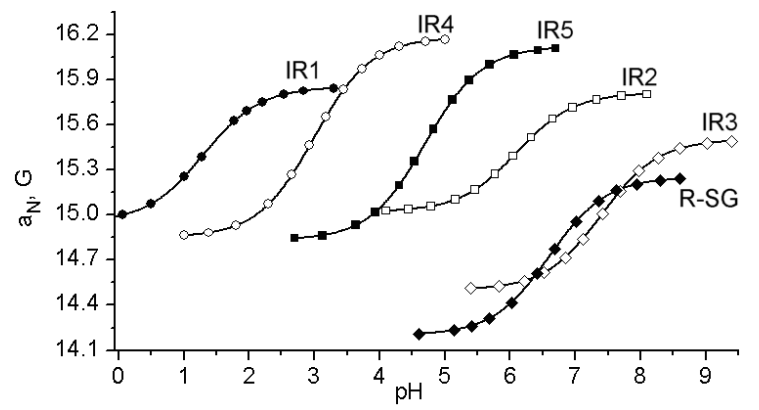

Figure 11. Nitroxides as molecular $\mathrm{pH}$ sensors. $\mathrm{pH}$ dependencies of nitrogen hyperfine splitting, aN, obtained using X-band EPR for the imidazoline and imidazolidine nitroxides IR1-IR5 (Scheme 5) and RSG (Scheme 3).

\subsubsection{In vivo $\mathrm{pH}$ monitoring using $\mathrm{pH}$-sensitive nitroxides}

Low-field EPR spectroscopy using spin $\mathrm{pH}$ probes has been shown to be a valuable tool for in vivo $\mathrm{pH}$ monitoring in organs and small animals such as rodents (Gallez et al., 1996b; Mader et al., 1996; Khramtsov et al., 2000; Foster et al., 2003; Potapenko et al., 2006; Bobko et al., 2012; Komarov et al., 2012). Figure 12a shows the structure of the nitroxide IR6 with
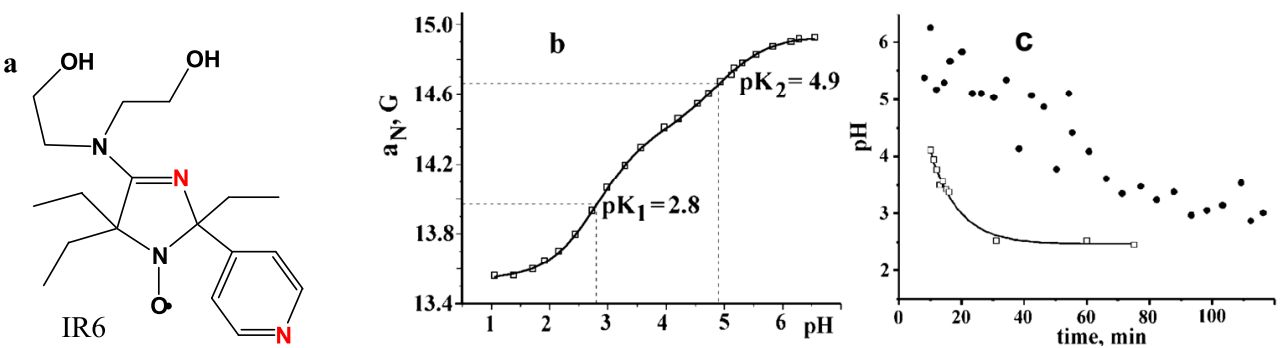

Figure 12. In vivo EPR monitoring of stomach acidity. (a) Chemical structure of imidazoline nitroxide IR6. Two protonatable nitrogen atoms are shown in red. (b) The $\mathrm{pH}$ dependence of hyperfine splitting, an, measured from $300 \mathrm{MHz}$ EPR spectra of IR6. The solid line was calculated according to the standard titration equation for the compound with two ionizable groups. The extended $\mathrm{pH}$ sensitivity range from $\mathrm{pH} 1.8$ to $\mathrm{pH} 6$ is ideally optimized for monitoring stomach acidity. (c) Changes in the stomach acidity of living rat measured by longitudinally detected EPR spectrometer operated at $304 \mathrm{MHz}$ excitation frequency, after giving $3 \mathrm{ml}$ of gavage containing $5 \mathrm{mM}$ IR6 probe alone ( $\square$ ) or with $50 \mathrm{mM}$ bicarbonate (•). From (Potapenko et al., 2006) with permission, copyright 2006, Elsevier Inc. 
properties optimized for monitoring stomach acidity (Potapenko et al., 2006). The presence of bulky groups in the vicinity of the NO fragment enhanced IR6 stability towards reduction, resulting in about four fold increase of its lifetime in vivo compared with that for previously used IR3 (Gallez et al., 1996b; Foster et al., 2003). The presence of two ionizable groups in the IR6 structure, imino nitrogen N-3 and pyridine, extended its range of $\mathrm{pH}$ sensitivity (see Fig. 12b). The hydrophilic character of pyridine, hydroxy, and amino groups of the IR6 probe prevents its penetration through biomembranes and probe redistribution from the stomach. Fig. 12c demonstrates real-time measurements of the stomach acidity in living rats using $300 \mathrm{MHz}$ EPR and IR6 probe (Potapenko et al., 2006). Long lifetime of the IR6 probe in vivo allows for monitoring drug-induced perturbation of stomach acidity and its normalization afterwards for periods of $1 \mathrm{~h}$ or longer, therefore supporting applicability of $\mathrm{pH}$ sensitive NRs to the studies of drug pharmacology and disease in living animals.

The acidic extracellular $\mathrm{pH}\left(\mathrm{pH}_{\mathrm{e}}\right)$ in tumors has a number of important consequences, playing a role in tumor initiation, progression, and therapy (Gillies et al., 2004). To be used for monitoring of tumor extracellular tissue acidosis, the nitroxide $\mathrm{pH}$ probe has to (i) possess $\mathrm{pH}$-sensitive spectral properties in the $\mathrm{pH}$ range from about 6.5 to 7.2 , (ii) have enhanced stability to survive a reducing tumor microenvironment, and (iii) not penetrate cellular membranes to ensure probe targeting to extracellular space. These properties were achieved by synthesizing RSG nitroxide (Scheme 3) with $\mathrm{pK}_{\mathrm{a}} \approx 6.6$ (Fig. 11) being ideally fitted for detection of extracellular tumor tissue acidity. The bulky ethyl substitutes at positions 2 and 5 around the NO fragment of the RSG are introduced to enhance its stability towards bioreduction (Kirilyuk et al., 2004). The binding of the radical to hydrophilic tripeptide, GSH, prevents probe diffusion across the plasma membrane, and therefore, enforces probe localization to extracellular aqueous volumes (Woldman et al., 2009). Recently the RSG probe has been used to monitor tissue $\mathrm{pHe}$ in mice bearing breast cancer tumors for assessment of therapeutic effectiveness of various treatments (Bobko et al., 2012). It was observed that tumor $\mathrm{pHe}$ is about $0.4 \mathrm{pH}$ units lower than in normal mammary gland tissue in agreement with microelectrode data (see Table 1). Note that RSG nitroxide can be used as a dual function $\mathrm{pH}$ and redox probe allowing for concurrent in vivo monitoring of both parameters (see section 2.2.1, Fig. 6).

\begin{tabular}{c|c|c|c}
\hline \multirow{2}{*}{} & \multicolumn{3}{|c}{$\mathrm{pH}$ values measured in tumors and mammary glands } \\
& L-band EPR & $\mathrm{pH}$ microelectrode & PEDRI \\
\hline Tumor & $6.60 \pm 0.07(\mathrm{n}=3)$ & $6.70 \pm 0.05(\mathrm{n}=3)$ & $6.7 \pm 0.1$ \\
Gland & $6.98 \pm 0.05(\mathrm{n}=3)$ & $7.01 \pm 0.05(\mathrm{n}=3)$ & $7.1 \pm 0.1$ \\
\hline
\end{tabular}

Table 1. Average $\mathrm{pH}$ values measured in tumor and mammary gland tissues in wild type $\mathrm{C} 57 \mathrm{Bl} / 6$ mice using different techniques (Bobko et al., 2012).

The enhanced stability of the RSG probe allowed for development of an EPR approach for monitoring ischemia-induced acidosis in isolated perfused rat hearts (Komarov et al., 2012). RSG probe demonstrated excellent EPR signal stability in the heart while $90 \%$ of the previously used IR2 probe (Khramtsov, 2005) was reduced in myocardial tissue within 5 minutes. As seen in Figure 13 ischemic preconditioning improved $\mathrm{pH}$ homeostasis during 
the global no-flow ischemia. Similar kinetics of myocardial acidification observed by the cell-impermeable RSG and cell-permeable IR2 probes support fast $\mathrm{pH}$ equilibration between intracellular and extracellular spaces in agreement with data obtained previously using glass microelectrodes and ${ }^{31}$ P-NMR (Asimakis et al., 1992; Lundmark et al., 1999).

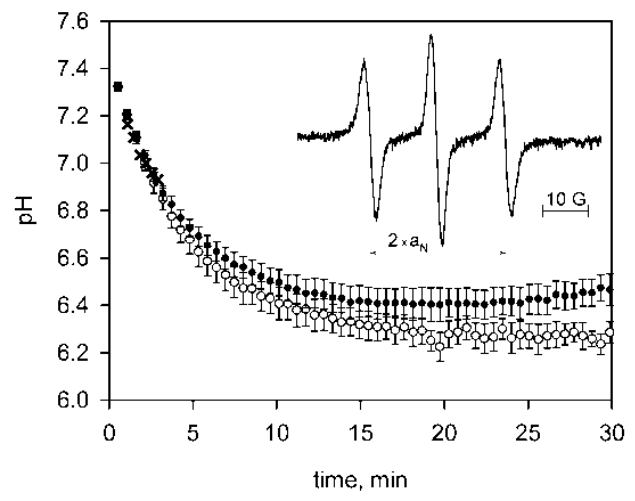

Figure 13. Ischemia-induced myocardial acidosis measured during global no-flow ischemia in control $(\circ)$ and ischemic preconditioned perfused rat hearts $(\bullet)$ using L-band EPR and nitroxide pH probes. The data obtained during first five minutes of ischemia using IR2 probe are denoted by $(\times)$ symbols. Preconditioned hearts were subjected to two episodes of five minutes ischemia followed by five minutes of reperfusion. The probes $(1.5 \mathrm{mM})$ were infused into the hearts through side arm of the perfusate line upon onset of global ischemia. Data are mean \pm S.E.; $n=6$. From (Komarov et al., 2012) with permission from John Wiley \& Sons, Ltd.

\subsection{3. $\mathrm{pH}$ mapping of living tissues}

Spatially-resolved in vivo $\mathrm{pH}$ measurement is critically important to allow for identification of the area with compromised $\mathrm{pH}$ homeostasis. Low-field CW EPRI allows for $\mathrm{pH}$ mapping of living tissues in small animals such as rodents. However loss in EPR sensitivity at low frequency aggravated by necessity of acquisition of numerous spectral projections with a variable strength of field gradients significantly limits spatial and temporal resolution of the approach. Application of low-field EPR spectra detection at high modulation amplitude provides significant improvement in spectral intensity and functional sensitivity allowing easy conversion of the 'position' image of the low- or high-field spectral component to ' $\mathrm{pH}$ map' with a good spatial $(0.2 \mathrm{~mm})$ and functional $(0.2 \mathrm{pH}$ units $)$ resolution as was demonstrated for phantom samples (Khramtsov et al., 2004, 2005).

Figure 14 demonstrates in vivo application of CW EPRI for tumor $\mathrm{pH}$ mapping. 3D EPR $\mathrm{pH}$ map was superimposed with co-registered MRI measured in right hind leg of $\mathrm{C} 3 \mathrm{H}$ mouse bearing squamous cell carcinoma after i.v. injection of RSG probe (Goodwin et al., 2012). EPR-measured $\mathrm{pHe}$ values show higher heterogeneity in tumor compared with normal tissue with mean $\mathrm{pHe}_{\mathrm{e}} 6.67$, significantly lower than mean tissue $\mathrm{pHe}$ in healthy leg, 7.17 . 


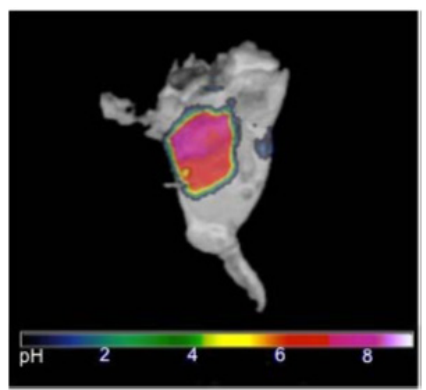

Figure 14. Co-registered EPR $\mathrm{pH}$ map and MRI of right hind leg of $\mathrm{C} 3 \mathrm{H}$ mouse bearing squamous cell carcinoma. A 4D (1×spectral, 3×spatial) CW EPRI (750 MHz) of low field and high field EPR peaks were performed using the following parameters: scan time, $0.3 \mathrm{~s}$; modulation amplitude, $1.5 \mathrm{G} ; \mathrm{Gmax}, 16 \mathrm{G} / \mathrm{cm}$; FOV, $5.09 \mathrm{~cm}$; projections, 576, total acquisition time, $\approx 6 \mathrm{~min}$. EPR $\mathrm{pH}$ map was superimposed with Varian 7T MRI image. Adapted from (Goodwin et al., 2012).

Recently we made significant progress towards $\mathrm{pH}$ mapping of living tissue using functional PEDRI approaches (Khramtsov et al., 2010; Efimova et al., 2011). Fig. 15 demonstrates PEDRI pH mapping of a tumor-bearing mouse after injection of deuterated analog of the RSG radical in tumor and mammary gland. The deuterated probe (see Fig. 15) has a narrower linewidth $\left(\Delta \mathrm{H}_{\mathrm{pp}}=1.2 \mathrm{G}\right)$ than RSG $\left(\Delta \mathrm{H}_{\mathrm{pp}}=2.1 \mathrm{G}\right)$, and therefore higher spectral intensity. The EPR signal of the deuterated RSG probe is easily saturated by RF irradiation which is of critical importance for PEDRI experiments. In total, more than one order decrease in acquisition time was achieved for PEDRI pH mapping (24.8 s in Fig. 15)
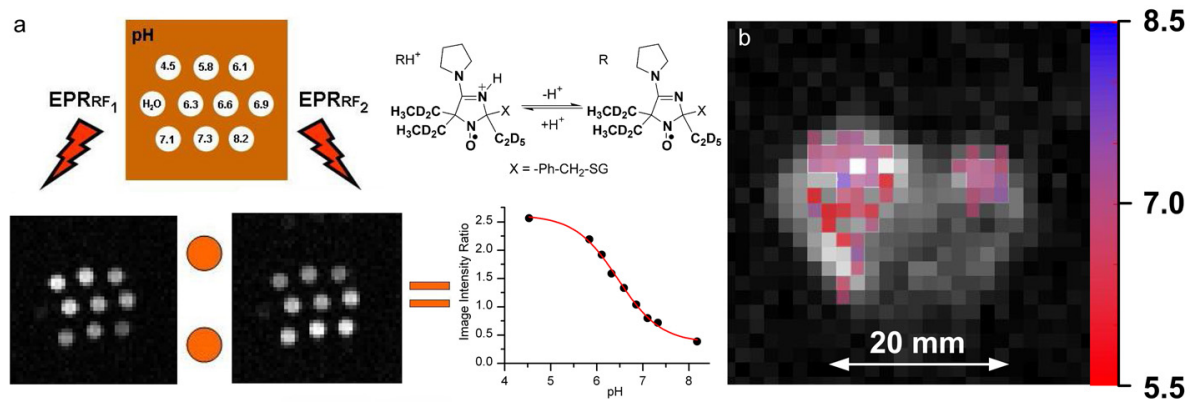

Figure 15. (a) Illustration of variable radio frequency PEDRI approach for the case of $\mathrm{pH}$-mapping. Two PEDRI images of the phantom were acquired during EPR irradiation (8.4 s) at two pre-selected EPR frequencies, $\mathrm{RF}_{1}=559.3 \mathrm{MHz}$ and $\mathrm{RF}_{2}=562.1 \mathrm{MHz}$ which correspond to EPR resonances of $\mathrm{RH}^{+}$and $\mathrm{R}$ forms of deuterated RSG probe. $\mathrm{pH}$ values of $1 \mathrm{mM}$ solutions of RSG are indicated on the phantom picture. Calibration curve was calculated as $\mathrm{pH}$ dependence of the ratio of signal amplitudes, $\mathrm{I}\left(\mathrm{RF}_{1}\right) / \mathrm{I}\left(\mathrm{RF}_{2}\right)$. (b) $\mathrm{pHe}$ mapping of living mouse by PEDRI. $\mathrm{pH}$ map (in color) was superimposed with low-field MRI (gray scale) showing the transvers view of the mouse. The $\mathrm{pH}$ probe was injected into the number 4 mammary gland containing tumor (left) and in the number 9 normal mammary gland (right) before PEDRI/MRI acquisitions. The $\mathrm{pH}$ map was calculated from two PEDRI images, acquired during EPR irradiation at two EPR frequencies, $\mathrm{RF}_{1}$ and $\mathrm{RF}_{2}$. Total acquisition, $24.8 \mathrm{~s}$. From (Bobko et al., 2012) with permission from John Wiley \& Sons, Ltd. 
compared with CW EPRI. Two areas of probe localization correspond to tumor (Fig. 15b left) and mammary gland (Fig. 15b right) with higher $\mathrm{pH}$ heterogeneity in tumor. Mean $\mathrm{pHe}$ values in tumor and mammary gland were found to be in agreement with EPR spectroscopy and microelectrode data measured in the same mice (see Table 1). The PEDRI functional approach may find applications for $\mathrm{pH}$ mapping of other living tissues and has potential for applications to humans.

\subsection{In vivo assessment of nitric oxide using nitronyl nitroxides}

The measurement of nitric oxide in vivo is of paramount importance due to its key role as a signaling molecule in numerous physiological and pathophysiological processes. Methods for NO detection in biological systems are limited because of its short half-life and low concentration in living systems. Fe(II)-dithiocarbamate complexes (Mordvintcev et al., 1991), widely used for NO detection by EPR spectroscopy, have an important advantage of relative stability of the paramagnetic adduct with NO. However, disadvantages of the approach include the preparation of metal-chelator complexes from two components, which are accompanied by both iron and dithiocarbamate moiety toxicities. Application of simple lowmolecular weight nitronyl nitroxides (NNRs) as NO-sensitive probes seems to be very attractive. The scavenging of nitric oxide by NNRs has been used for NO detection by EPR spectroscopy and to antagonize biological actions of nitric oxide (Akaike et al., 1993; Joseph et al., 1993; Woldman et al., 1994; Blasig et al., 2002; Cao \& Reith, 2002). The detection of NO using NNR is based on the specific radical-radical reaction (see Fig.16a) followed by EPRmeasured spectra changes.

The physiological effects of NNR cannot be entirely explained by their specific radicalradical reactions with nitric oxide due to the rapid reduction of NNR to its corresponding hydroxylamines. The performed mechanistic studies of the NNR reaction with NO in a reducing environment (Bobko et al., 2004) demonstrate an ability of the NNR to react with NO in the presence of the reducing agent, ascorbate, as shown in Figure 16b. It has been shown that equilibrium between radical, NNR, and its hydroxylamine is normally strongly shifted towards diamagnetic hydroxylamine, therefore no initial EPR spectra were observed in the presence of ascorbate (Fig. 16b). However NO generation and its consequent reaction with NNR results in accumulation of paramagnetic NNR and appearance of the corresponding EPR spectra (Fig. 16b, 3min). During the reaction, NNR is transformed to INR followed by characteristic changes of EPR spectral pattern (Fig. 16b, 6 and $9 \mathrm{~min}$ ). After the reaction was complete, INR was reduced in its diamagnetic form by ascorbate (Fig. 16b, $20 \mathrm{~min}$ ). The presence of fluorine atoms in the structure of fNNR allowed us to monitor accumulation of diamagnetic hydroxylamine product by ${ }^{19} \mathrm{~F}$ NMR spectroscopy providing additional proof of the redox-sensitive mechanism of the NNR reaction with NO. The corresponding scheme of the reactions provides a plausible mechanism explaining the antagonistic action of NNR against NO in a reducing environment, a phenomenon well documented in vivo (for details see ref. (Bobko et al., 2004)). 
a

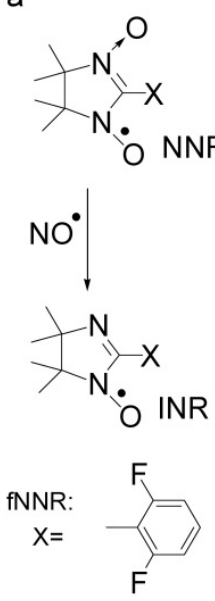

b fNNR + ascorbate

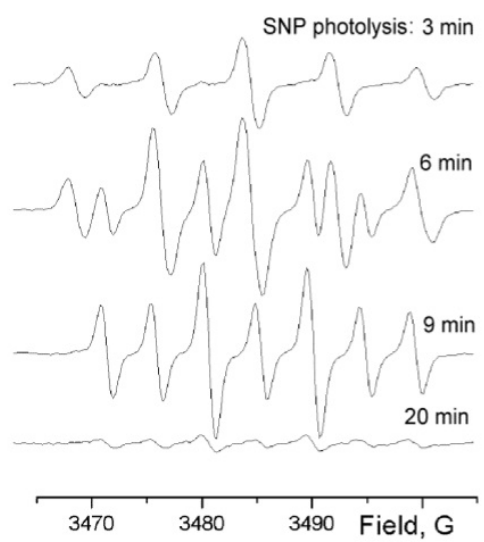

Figure 16. (a) The scheme of the reaction of nitronyl nitroxides, NNR, with NO forming iminonitroxides, INR. (b) NO-induced EPR spectral changes measured for fluorinated NNR derivative, fNNR, in the presence of reducing agent, ascorbate. Nitric oxide was generated upon photolysis of sodium nitroprusside (SNP). The spectra were measured in the mixture of $3.33 \mathrm{mM} f N N R, 3.33 \mathrm{mM}$ ascorbate and $33.3 \mathrm{mM}$ SNP before and after SNP photolysis. From (Bobko et al., 2004) with permission, copyright 2003, Elsevier Inc.

The application of NNR for NO detection by EPR in biological systems with physiologically low rates of $\mathrm{NO}$ generation is limited due to the very rapid reduction of NNR, and particularly of INR, into diamagnetic EPR-silent product (Woldman et al., 1994; Haseloff et al., 1997; Bobko et al., 2004), so equilibrium radical concentration is lower than threshold of EPR detection. An alternative approach for NO detection using NNR is based on application of fluorinated NNRs, such as fNNR, in combination with ${ }^{19} \mathrm{~F}$ NMR spectroscopy. An in vivo accumulation of the product of the reaction of fNNR with NO, hydroxylamine of fINR can be measured by ${ }^{19} \mathrm{~F}$ NMR. Low $\mathrm{NO}$ concentrations in living tissues and low intrinsic NMR sensitivity make this approach hardly applicable in vivo. Nevertheless, stability of the diamagnetic fINR product allows for its in vivo accumulation followed by ex vivo ${ }^{19} \mathrm{~F}$ NMR measurement. The $e x$ vivo ${ }^{19} \mathrm{~F}$ NMR measurement of fluorinated hydroxylamine products in blood samples taken from normotensive and hypertensive rats $1 \mathrm{hr}$ after intraperitoneal injection of fNNR positively correlated with the levels of nitrite/nitrate evaluated by Griess method and negatively correlated with the blood pressure (Bobko et al., 2005). While ${ }^{19} \mathrm{~F}$ NMR spectroscopy allows ex vivo evaluation of NO production, the development of NNR structures with higher stability for EPR detection in vivo is desirable. Several attempts by our group and others to protect NNR against reduction via encapsulation in liposomal (Woldman et al., 1994; Bobko et al., 2010) or dendrimeric (Rosen et al., 2003) structures resulted in significant lifetime increase but further work has to be done to obtain NNR probes stable enough for in vivo applications. 


\section{Conclusion}

In recent decades functional EPR spectroscopy and imaging applications have moved closer to biomedical applicability. The bottleneck of in vivo EPR-based applications is the requirement of appropriate paramagnetic probes. NRs and triarylmethyl radicals, TAMs, represent two main classes of soluble paramagnetic materials used for EPR spectroscopy and imaging applications (Khramtsov \& Zweier, 2010). TAMs have advantages over nitroxides in extraordinary stability toward tissue redox processes, longer relaxation time and narrower line width making them particularly attractive for imaging applications. Applications of TAM radicals as functional probes include EPR oximetry (ArdenkjaerLarsen et al., 1998; Golman et al., 2000; Krishna et al., 2002) and recently reported sensitivity to the superoxide anion (Kutala et al., 2004; Kutala et al., 2008) and pH (Bobko et al., 2007a; Dhimitruka et al., 2008; Driesschaert et al., 2012). On the other hand NRs have tremendous advantage over TAMs in well-developed chemistry. As a consequence, the nitroxides provide a wide range of available structures that vary in solubility and tissue redistribution, spectral and functional sensitivity, ability to be targeted and lifetimes in living tissues. Specific nitroxides provide EPR-based spectroscopy and imaging with the capacity for functional temporally and spatially resolved mapping of physiologically relevant parameters of living tissues, such as oxygen, redox status, glutathione content and $\mathrm{pH}$. The nitroxides were the first compounds applied to EPR oximetry and are still a useful tool for in vivo tissue oxygen mapping. The most well known reaction of the nitroxides, their reduction to EPR-silent hydroxylamines, provides information on redox state in living tissues. The disulfide biradical nitroxides were developed for in vivo assessment of intracellular glutathione concentration. The imidazoline nitroxide spin $\mathrm{pH}$ probes allowed for EPR spectroscopy and imaging of tissue pH. NanoSized Particles with Incorporated Nitroxides, or nanoSPINs, may serve as a future platform for stabilized nitroxide-based biosensors (Woldman et al., 2009). In particular, encapsulation of NO-sensitive nitronyl nitroxides may protect the sensing probe from biological reductants while retaining sensitivity to a small analyte, molecule of nitric oxide. In summary, the area of nitroxide biomedical application as functional paramagnetic probes is truly emerging.

\section{Author details}

Valery V. Khramtsov

Division of Pulmonary, Allergy, Critical Care \& Sleep Medicine, Department of Internal Medicine, The Ohio State University, Columbus, $\mathrm{OH}, \mathrm{USA}$

\section{Acknowledgement}

This work was partly supported by NIH Grant EB014542-01A1. VVK thanks Dr. Andrey Bobko for technical assistance and helpful discussion. 


\section{References}

Akaike, T., Yoshida, M., Miyamoto, Y., Sato, K., Kohno, M., Sasamoto, K., Miyazaki, K., Ueda, S. and Maeda, H. (1993). Antagonistic action of imidazolineoxyl N-oxides against endothelium-derived relaxing factor/.NO through a radical reaction. Biochemistry, Vol. 32, No 3, pp. 827-32.

Ardenkjaer-Larsen, J. H., Laursen, I., Leunbach, I., Ehnholm, G., Wistrand, L. G., Petersson, J. S. and Golman, K. (1998). EPR and DNP properties of certain novel single electron contrast agents intended for oximetric imaging. J Magn Reson, Vol. 133, No 1, pp. 1-12.

Asimakis, G. K., Inners-McBride, K., Medellin, G. and Conti, V. R. (1992). Ischemic preconditioning attenuates acidosis and postischemic dysfunction in isolated rat heart. Am J Physiol, Vol. 263, No 3 Pt 2, pp. H887-94.

Bacic, G., Nilges, M. J., Magin, R. L., Walczak, T. and Swartz, H. M. (1989). In vivo localized ESR spectroscopy reflecting metabolism. Magn Reson Med, Vol. 10, No 2, pp. 266-72.

Backer, J. M., Budker, V. G., Eremenko, S. I. and Molin, Y. N. (1977). Detection of the kinetics of biochemical reactions with oxygen using exchange broadening in the ESR spectra of nitroxide radicals. Biochim Biophys Acta, Vol. 460, No 1, pp. 152-6.

Baker, J. E., Froncisz, W., Joseph, J. and Kalyanaraman, B. (1997). Spin label oximetry to assess extracellular oxygen during myocardial ischemia. Free Radic Biol Med, Vol. 22, No 1-2, pp. 109-15.

Berliner, L. J., Ed. (1998). Spin Labeling. The Next Millennium. New York, London, Plenum Press, $423 \mathrm{p}$.

Blasig, I. E., Mertsch, K. and Haseloff, R. F. (2002). Nitronyl nitroxides, a novel group of protective agents against oxidative stress in endothelial cells forming the blood-brain barrier. Neuropharmacology, Vol. 43, No 6, pp. 1006-14.

Bobko, A. A., Bagryanskaya, E. G., Reznikov, V. A., Kolosova, N. G., Clanton, T. L. and Khramtsov, V. V. (2004). Redox-sensitive mechanism of no scavenging by nitronyl nitroxides. Free Radic Biol Med, Vol. 36, No 2, pp. 248-58.

Bobko, A. A., Sergeeva, S. V., Bagryanskaya, E. G., Markel, A. L., Khramtsov, V. V., Reznikov, V. A. and Kolosova, N. G. (2005). 19F NMR measurements of NO production in hypertensive ISIAH and OXYS rats. Biochem Biophys Res Commun, Vol. 330, No 2, pp. 367-70.

Bobko, A. A., Dhimitruka, I., Zweier, J. L. and Khramtsov, V. V. (2007a). Trityl radicals as persistent dual function $\mathrm{pH}$ and oxygen probes for in vivo electron paramagnetic resonance spectroscopy and imaging: concept and experiment. J Am Chem Soc, Vol. 129, No 23, pp. 7240-1.

Bobko, A. A., Kirilyuk, I. A., Grigor'ev, I. A., Zweier, J. L. and Khramtsov, V. V. (2007b). Reversible Reduction of Nitroxides to Hydroxylamines: the Roles for Ascorbate and Glutathione. Free Rad. Biol. Med., Vol. 42 No. 3, pp. 404-12.

Bobko, A. A., Dhimitruka, I., Eubank, T. D., Marsh, C. B., Zweier, J. L. and Khramtsov, V. V. (2009). Trityl-based EPR probe with enhanced sensitivity to oxygen. Free Radic Biol Med, Vol. 47, No 5, pp. 654-8. 
Bobko, A. A., Ivanov, A. and Khramstov, V. V. (2010). Discriminating detection of NO and HNO using encapsulated nitronyl nitroxides. Free Radic Biol Med, Vol. 49 (Suppl.1), p. S109.

Bobko, A. A., Eubank, T. D., Voorhees, J. L., Efimova, O. V., Kirilyuk, I. A., Petryakov, S., Trofimiov, D. G., Marsh, C. B., Zweier, J. L., Grigor'ev, I. A., Samouilov, A. and Khramtsov, V. V. (2012). In vivo monitoring of $\mathrm{pH}$, redox status, and glutathione using L-band EPR for assessment of therapeutic effectiveness in solid tumors. Magn Reson Med, doi: 10.1002/mrm.23196.

Bratasz, A., Selvendiran, K., Wasowicz, T., Bobko, A., Khramtsov, V. V., Ignarro, L. J. and Kuppusamy, P. (2008). NCX-4040, a nitric oxide-releasing aspirin, sensitizes drugresistant human ovarian xenograft tumors to cisplatin by depletion of cellular thiols. Journal of Translational Medicine, Vol. 6, No 9. doi: 10.1186/1479-5876-6-9.

Cao, B. J. and Reith, M. E. (2002). Nitric oxide scavenger carboxy-PTIO potentiates the inhibition of dopamine uptake by nitric oxide donors. Eur J Pharmacol, Vol. 448, No 1, pp. 27-30.

Chan, H. C., Glockner, J. F. and Swartz, H. M. (1989). Oximetry in cells and tissues using a nitroxide-liposome system. Biochim Biophys Acta, Vol. 1014, No 2, pp. 141-4.

Clarkson, R. B., Odintsov, B. M., Ceroke, P. J., Ardenkjaer-Larsen, J. H., Fruianu, M. and Belford, R. L. (1998). Electron paramagnetic resonance and dynamic nuclear polarization of char suspensions: surface science and oximetry. Phys Med Biol, Vol. 43, No 7, pp. 1907-20.

Cook, J. A., Gius, D., Wink, D. A., Krishna, M. C., Russo, A. and Mitchell, J. B. (2004). Oxidative stress, redox, and the tumor microenvironment. Semin Radiat Oncol, Vol. 14, No 3, pp. 259-66.

Dhimitruka, I., Bobko, A. A., Hadad, C. M., Zweier, J. L. and Khramtsov, V. V. (2008). Synthesis and characterization of amino derivatives of persistent trityl radicals as dual function $\mathrm{pH}$ and oxygen paramagnetic probes. J Am Chem Soc, Vol. 130, No 32, pp. 10780-7.

Driesschaert, B., Marchand, V., Levêque, P., Gallez, B. and Marchand-Brynaert, J. (2012). Phosphonated Triarylmethyl Radical as Probe for Measurement of $\mathrm{pH}$ by EPR. Chem. Commun., Vol. 48, pp. 4049-51. DOI: 10.1039/C2CC00025C.

Efimova, O. V., Sun, Z., Petryakov, S., Kesselring, E., Caia, G. L., Johnson, D., Zweier, J. L., Khramtsov, V. V. and Samouilov, A. (2011). Variable Radio Frequency Proton-Electron Double-Resonance Imaging: application to $\mathrm{pH}$ mapping of aqueous samples. J Magn Reson, Vol. 209, No 2, pp. 227-232.

Ellman, G. L. (1959). Tissue sulfhydryl groups. Arch Biochem Biophys, Vol. 82, No 1, pp. 70-7.

Eubank, T. D., Roberts, R. D., Khan, M., Curry, J. M., Nuovo, G. J., Kuppusamy, P. and Marsh, C. B. (2009). Granulocyte macrophage colony-stimulating factor inhibits breast cancer growth and metastasis by invoking an anti-angiogenic program in tumoreducated macrophages. Cancer Res, Vol. 69, No 5, pp. 2133-40.

Finkelstein, E., Rosen, G. M. and Rauckman, E. J. (1984). Superoxide-dependent reduction of nitroxides by thiols. Biochim. Biophys. Acta, Vol. 802, No, pp. 90-98. 
Foster, M. A., Grigor'ev, I. A., Lurie, D. J., Khramtsov, V. V., McCallum, S., Panagiotelis, I., Hutchison, J. M., Koptioug, A. and Nicholson, I. (2003). In vivo detection of a pHsensitive nitroxide in the rat stomach by low-field ESR-based techniques. Magn Reson Med, Vol. 49, No 3, pp. 558-67.

Froncisz, W., Lai, C. S. and Hyde, J. S. (1985). Spin-label oximetry: kinetic study of cell respiration using a rapid-passage T1-sensitive electron spin resonance display. Proc Natl Acad Sci U S A, Vol. 82, No 2, pp. 411-5.

Gallez, B., Debuyst, R., Demeure, R., Dejehet, F., Grandin, C., Van Beers, B., Taper, H., Pringot, J. and Dumont, P. (1993). Evaluation of a nitroxyl fatty acid as liver contrast agent for magnetic resonance imaging. Magn Reson Med, Vol. 30, No 5, pp. 592-9.

Gallez, B., Bacic, G., Goda, F., Jiang, J., O'Hara, J. A., Dunn, J. F. and Swartz, H. M. (1996a). Use of nitroxides for assessing perfusion, oxygenation, and viability of tissues: in vivo EPR and MRI studies. Magn Reson Med, Vol. 35, No 1, pp. 97-106.

Gallez, B., Mader, K. and Swartz, H. M. (1996b). Noninvasive measurement of the pH inside the gut by using $\mathrm{pH}$-sensitive nitroxides. An in vivo EPR study. Magn Reson Med, Vol. 36, No 5, pp. 694-7.

Gillies, R. J., Alger, J. R., den Hollander, J. A. and Shulman, R. G. (1982). Intracellular pH measured by NMR: methods and results, In: Intracellular $\mathrm{pH}$ : Its measurement, regulation and utilization in cellular functions. R. Nuccitelli, Deamer, D. W. (Ed.): 79-104, New York, Alan R.Liss.

Gillies, R. J., Liu, Z. and Bhujwalla, Z. (1994). 31P-MRS measurements of extracellular pH of tumors using 3-aminopropylphosphonate. Am J Physiol, Vol. 267, No 1 Pt 1, pp. C195203.

Gillies, R. J., Raghunand, N., Garcia-Martin, M. L. and Gatenby, R. A. (2004). pH imaging. A review of $\mathrm{pH}$ measurement methods and applications in cancers. IEEE Eng Med Biol Mag, Vol. 23, No 5, pp. 57-64.

Glebska, J., Skolimowski, J., Kudzin, Z., Gwozdzinski, K., Grzelak, A. and Bartosz, G. (2003). Pro-oxidative activity of nitroxides in their reactions with glutathione. Free Radic Biol Med, Vol. 35, No 3, pp. 310-6.

Glockner, J. F., Norby, S. W. and Swartz, H. M. (1993). Simultaneous measurement of intracellular and extracellular oxygen concentrations using a nitroxide-liposome system. Magn Reson Med, Vol. 29, No 1, pp. 12-8.

Golman, K., Petersson, J. S., Ardenkjaer-Larsen, J. H., Leunbach, I., Wistrand, L. G., Ehnholm, G. and Liu, K. J. (2000). Dynamic in vivo oxymetry using overhauser enhanced MR imaging. J Magn Reson Imaging, Vol. 12, No, pp. 929-938.

Goodwin, J., Koda, S., Ohfuchi, M., Pawlak, A., Yasui, H., Khramstov, V. and Hirata, H. (2012). Four-dimensional spectral spatial $\mathrm{pH}$ mapping of mouse tumour using Continuous Wave-Electron Paramagnetic Resonance imaging (CW-EPRI) and $\mathrm{pH}$ sensitive imidazoline nitroxide, In: Proceedings of 20th Annual Meeting of the International Society for Magnetic Resonance in Medicine, \# 1708, Melbourne, Australia.

Grucker, D. and Chambron, J. (1993). Oxygen imaging in perfused hearts by dynamic nuclear polarization. Magn Reson Imaging, Vol. 11, No 5, pp. 691-6. 
Halpern, H. J., Yu, C., Peric, M., Barth, E., Grdina, D. J. and Teicher, B. A. (1994). Oxymetry deep in tissues with low-frequency electron paramagnetic resonance. Proc Natl Acad Sci U S A, Vol. 91, No 26, pp. 13047-51.

Haseloff, R. F., Zollner, S., Kirilyuk, I. A., Grigor'ev, I. A., Reszka, R., Bernhardt, R., Mertsch, K., Roloff, B. and Blasig, I. E. (1997). Superoxide-mediated reduction of the nitroxide group can prevent detection of nitric oxide by nitronyl nitroxides. Free Radic Res, Vol. 26, No 1, pp. 7-17.

He, G., Samouilov, A., Kuppusamy, P. and Zweier, J. L. (2002). In vivo imaging of free radicals: applications from mouse to man. Mol Cell Biochem, Vol. 234-235, No 1-2, pp. 359-67.

He, G., Kutala, V. K., Kuppusamy, P. and Zweier, J. L. (2004). In vivo measurement and mapping of skin redox stress induced by ultraviolet light exposure. Free Radic Biol Med, Vol. 36, No 5, pp. 665-72.

Hideg, K., Kalai, T. and Sar, C. P. (2005). Recent results in chemistry and biology of nitroxides. J. Heterocycl. Chem., Vol. 42, No, pp. 437-450.

Hoffman, B. M. and Eames, T. B. (1969). Protonated nitroxide free radical. J Am Chem Soc, Vol. 91, No, pp. 2169-2170.

Hsia, J. C. and Boggs, J. M. (1972). Influence of $\mathrm{pH}$ and cholesterol on the structure of phosphatidylethanolamine multibilayers. Biochim Biophys Acta, Vol. 266, No 1, pp. 1825.

Hubbell, W. L., Cafiso, D. S. and Altenbach, C. (2000). Identifying conformational changes with site-directed spin labeling. Nat Struct Biol, Vol. 7, No 9, pp. 735-9.

Hyde, J. S. and Subszynski, W. K. (1989). Spin label oximetry., In: Spin Labeling: Theory and Application. L. J. Berliner and J. Reubens (Ed.), 8: 399-425, New York, Plenum Press.

Hyde, J. S., Jin, J.-J., Felix, J. B. and Hubbell, W. L. (1990). Advances in spin label oximetry. Pure E Applied Chem., Vol. 62, No, pp. 255-260.

Hyodo, F., Murugesan, R., Matsumoto, K., Hyodo, E., Subramanian, S., Mitchell, J. B. and Krishna, M. C. (2008). Monitoring redox-sensitive paramagnetic contrast agent by EPRI, OMRI and MRI. J Magn Reson, Vol. 190, No 1, pp. 105-12.

Hyodo, F., Matsumoto, S., Devasahayam, N., Dharmaraj, C., Subramanian, S., Mitchell, J. B. and Krishna, M. C. (2009). Pulsed EPR imaging of nitroxides in mice. J Magn Reson, Vol. 197, No 2, pp. 181-5.

Joseph, J., Kalyanaraman, B. and Hyde, J. S. (1993). Trapping of nitric oxide by nitronyl nitroxides: an electron spin resonance investigation. Biochem Biophys Res Commun, Vol. 192, No 2, pp. 926-34.

Karoui, H., Le Moigne, F., Ouari, O. and Tordo, P. (2010). Nitroxide Radicals: Properties, Synthesis and Applications, In: Stable Radicals. Fundamental and Applied Aspects of OddElectron Compounds. R. G. Hicks (Ed.): 173-229, Chichester, UK, John Wiley \& Sons, Ltd.

Khramtsov, V. V., Weiner, L. M., Grigor'ev, I. A. and Volodarsky, L. B. (1982). Proton exchange in stable nitroxyl radicals. EPR studies of the $\mathrm{pH}$ of aqueous solutions. Chem Phys Lett, Vol. 91, No, pp. 69-72. 
Khramtsov, V. V. and Weiner, L. M. (1988). Proton exchange in stable nitroxyl radicals: pH sensitive spin probes, In: Imidazoline nitroxides. L. B. Volodarsky (Ed.), 2: 37-80, Boca Raton, FL., CRC Press.

Khramtsov, V. V., Yelinova, V. I., Weiner, L. M., Berezina, T. A., Martin, V. V. and Volodarsky, L. B. (1989). Quantitative determination of SH groups in low- and highmolecular-weight compounds by an electron spin resonance method. Anal Biochem, Vol. 182, No 1, pp. 58-63.

Khramtsov, V. V., Yelinova, V. I., Glazachev Yu, I., Reznikov, V. A. and Zimmer, G. (1997). Quantitative determination and reversible modification of thiols using imidazolidine biradical disulfide label. J Biochem Biophys Methods, Vol. 35, No 2, pp. 115-28.

Khramtsov, V. V. and Volodarsky, L. B. (1998). Use of imidazoline nitroxides in studies of chemical reactions. ESR measurements of the concentration and reactivity of protons, thiols and nitric oxide, In: Spin labeling. The next Millennium. L. J. Berliner (Ed.), 14: 109180, New York, Plenum Press.

Khramtsov, V. V., Grigor'ev, I. A., Foster, M. A., Lurie, D. J. and Nicholson, I. (2000). Biological applications of spin $\mathrm{pH}$ probes. Cell Mol Biol, Vol. 46, No 8, pp. 1361-74.

Khramtsov, V. V., Grigor'ev, I. A., Foster, M. A., Lurie, D. J., Zweier, J. L. and Kuppusamy, P. (2004). Spin $\mathrm{pH}$ and SH probes: enhancing functionality of EPR-based techniques. Spectroscopy, Vol. 18, No, pp. 213-225.

Khramtsov, V. V. (2005). Biological imaging and spectroscopy of pH. Curr. Org. Chem., Vol. 9, No, pp. 909-923.

Khramtsov, V. V., Caia, G. L., Shet, K., Kesselring, E., Petryakov, S., Zweier, J. L. and Samouilov, A. (2010). Variable Field Proton-Electron Double-Resonance Imaging: Application to $\mathrm{pH}$ mapping of aqueous samples. J Magn Reson, Vol. 202, No 2, pp. 26773.

Khramtsov, V. V. and Zweier, J. L. (2010). Functional in vivo EPR Spectroscopy and Imaging Using Nitroxide and Trityl Radicals, In: Stable Radicals: Fundamentals and Applied Aspects of Odd-Electron Compounds. R. Hicks (Ed.): 537-566, Chichester, UK., John Wiley \& Sons, Ltd.

Khramtsov, V. V. and Komarov, D. A. (2011). Nanospin Probes and Applications to Cardiology, In: Nanomedicine and the Cardiovascular System. R. J. Hunter and V. R. Preedy (Ed.): 200-220, Enfield, NH, Science Publishers and CRC Press.

Kirilyuk, I. A., Bobko, A. A., Grigor'ev, I. A. and Khramtsov, V. V. (2004). Synthesis of the tetraethyl substituted $\mathrm{pH}$-sensitive nitroxides of imidazole series with enhanced stability towards reduction. Org Biomol Chem, Vol. 2, No 7, pp. 1025-30.

Kirilyuk, I. A., Bobko, A. A., Khramtsov, V. V. and Grigor'ev, I. A. (2005). Nitroxides with two $\mathrm{pK}$ values--useful spin probes for $\mathrm{pH}$ monitoring within a broad range. Org Biomol Chem, Vol. 3, No 7, pp. 1269-74.

Kocherginsky, N. and Swartz, H. M. (1995). Nitroxide spin labels. Reactions in biology and chemistry, CRC Press, Boca Raton, New York, London, Tokyo.

Komarov, D. A., Dhimitruka, I., Kirilyuk, I. A., Trofimiov, D. G., Grigor'ev, I. A., Zweier, J. L. and Khramtsov, V. V. (2012). Electron paramagnetic resonance monitoring of 
ischemia-induced myocardial oxygen depletion and acidosis in isolated rat hearts using soluble paramagnetic probes. Magn Reson Med, doi: 10.1002/mrm.23251.

Krishna, M. C., English, S., Yamada, K., Yoo, J., Murugesan, R., Devasahayam, N., Cook, J. A., Golman, K., Ardenkjaer-Larsen, J. H., Subramanian, S. and Mitchell, J. B. (2002). Overhauser enhanced magnetic resonance imaging for tumor oximetry: coregistration of tumor anatomy and tissue oxygen concentration. Proc Natl Acad Sci U S A, Vol. 99, No 4, pp. 2216-21.

Kuppusamy, P., Chzhan, M., Vij, K., Shteynbuk, M., Lefer, D. J., Giannella, E. and Zweier, J. L. (1994). Three-dimensional spectral-spatial EPR imaging of free radicals in the heart: a technique for imaging tissue metabolism and oxygenation. Proc Natl Acad Sci U S A, Vol. 91, No 8, pp. 3388-92.

Kuppusamy, P., Afeworki, M., Shankar, R. A., Coffin, D., Krishna, M. C., Hahn, S. M., Mitchell, J. B. and Zweier, J. L. (1998). In vivo electron paramagnetic resonance imaging of tumor heterogeneity and oxygenation in a murine model. Cancer Res, Vol.58, No 7, pp.1562-8.

Kuppusamy, P. and Krishna, M. C. (2002). EPR Imaging of tissue redox status. Current topics in Biophysics, Vol. 26, No, pp. 29-34.

Kuppusamy, P., Li, H., Ilangovan, G., Cardounel, A. J., Zweier, J. L., Yamada, K., Krishna, M. C. and Mitchell, J. B. (2002). Noninvasive imaging of tumor redox status and its modification by tissue glutathione levels. Cancer Res, Vol. 62, No 1, pp. 307-12.

Kuppusamy, P. and Zweier, J. L. (2004). Cardiac applications of EPR imaging. NMR Biomed, Vol. 17, No 5, pp. 226-39.

Kutala, V. K., Parinandi, N. L., Zweier, J. L. and Kuppusamy, P. (2004). Reaction of superoxide with trityl radical: implications for the determination of superoxide by spectrophotometry. Arch Biochem Biophys, Vol. 424, No 1, pp. 81-8.

Kutala, V. K., Villamena, F. A., Ilangovan, G., Maspoch, D., Roques, N., Veciana, J., Rovira, C. and Kuppusamy, P. (2008). Reactivity of superoxide anion radical with a perchlorotriphenylmethyl (trityl) radical. J Phys Chem B, Vol. 112, No 1, pp. 158-67.

Kveder, M., Krisko, A., Pifat, G. and Steinhoff, H. J. (2003). The study of structural accessibility of free thiol groups in human low-density lipoproteins. Biochim Biophys Acta, Vol. 1631, No 3, pp. 239-45.

Lai, C. S., Hopwood, L. E., Hyde, J. S. and Lukiewicz, S. (1982). ESR studies of $\mathrm{O}_{2}$ uptake by Chinese hamster ovary cells during the cell cycle. Proc Natl Acad Sci U S A, Vol. 79, No 4, pp. 1166-70.

Lebedev, O. A. and Kayanovskii, S. N. (1959). Catalytic oxidation of aliphatic amines with hydrogen peroxide. Trudy po Khimii i Khim Technologii (Gorkii), Vol. 8, No, pp. 649-652.

Lee, F. Y., Vessey, A., Rofstad, E., Siemann, D. W. and Sutherland, R. M. (1989). Heterogeneity of glutathione content in human ovarian cancer. Cancer Res, Vol. 49, No 19, pp. 5244-8.

Liu, K. J., Gast, P., Moussavi, M., Norby, S. W., Vahidi, N., Walczak, T., Wu, M. and Swartz, H. M. (1993). Lithium phthalocyanine: a probe for electron paramagnetic resonance oximetry in viable biological systems. Proc Natl Acad Sci U S A, Vol. 90, No 12, pp. 543842. 
Liu, K. J., Grinstaff, M. W., Jiang, J., Suslick, K. S., Swartz, H. M. and Wang, W. (1994). In vivo measurement of oxygen concentration using sonochemically synthesized microspheres. Biophys J, Vol. 67, No 2, pp. 896-901.

Livesey, J. C., Golden, R. N., Shankland, E. G., Grunbaum, Z., Wyman, M. and Krohn, K. A. (1992). Magnetic resonance spectroscopic measurement of cellular thiol reductionoxidation state. Int J Radiat Oncol Biol Phys, Vol. 22, No 4, pp. 755-7.

Lundmark, J. A., Trueblood, N., Wang, L. F., Ramasamy, R. and Schaefer, S. (1999). Repetitive acidosis protects the ischemic heart: implications for mechanisms in preconditioned hearts. J Mol Cell Cardiol, Vol. 31, No 4, pp. 907-17.

Mader, K., Gallez, B., Liu, K. J. and Swartz, H. M. (1996). Non-invasive in vivo characterization of release processes in biodegradable polymers by low-frequency electron paramagnetic resonance spectroscopy. Biomaterials, Vol. 17, No 4, pp. 457-61.

Malatesta, V. and Ingold, K. U. (1973). Protonated nitroxide radicals. J Am Chem Soc, Vol. 95, No, pp. 6404-6407.

Mathew, A. E. and Dodd, J. R. (1985). Synthesis of substituted, 2,2,5,5-tetramethylpyrrolidin1-oxyl spin labels. pH sensitivity studies. J. Heterocycl. Chem., Vol. 22, No, pp. 225-228.

Mordvintcev, P., Mulsch, A., Busse, R. and Vanin, A. (1991). On-line detection of nitric oxide formation in liquid aqueous phase by electron paramagnetic resonance spectroscopy. Anal Biochem, Vol. 199, No 1, pp. 142-6.

Murugesan, R., Cook, J. A., Devasahayam, N., Afeworki, M., Subramanian, S., Tschudin, R., Larsen, J. A., Mitchell, J. B., Russo, A. and Krishna, M. C. (1997). In vivo imaging of a stable paramagnetic probe by pulsed-radiofrequency electron paramagnetic resonance spectroscopy. Magn Reson Med, Vol. 38, No 3, pp. 409-14.

Nakaie, C. R., Goissis, G., Schreier, S. and Paiva, A. C. (1981). pH dependence of EPR spectra of nitroxides containing ionizable groups. Braz J Med Biol Res, Vol. 14, No 2-3, pp. 17380.

Neiman, M. B., Rozatzev, E. G. and Mamedova, Y. G. (1962). Free radical reactions involving no unpaired electrons. Nature, Vol. 196, No 3, pp. 472-474.

Ojha, N., Roy, S., He, G., Biswas, S., Velayutham, M., Khanna, S., Kuppusamy, P., Zweier, J. L. and Sen, C. K. (2008). Assessment of wound-site redox environment and the significance of Rac2 in cutaneous healing. Free Radic Biol Med, Vol. 44, No 4, pp. 682-91.

Patsoukis, N. and Georgiou, C. D. (2005). Fluorometric determination of thiol redox state. Anal Bioanal Chem, Vol. 383, No 6, pp. 923-9.

Pietri, S., Martel, S., Culcasi, M., Delmas-Beauvieux, M. C., Canioni, P. and Gallis, J. L. (2001). Use of diethyl(2-methylpyrrolidin-2-yl)phosphonate as a highly sensitive extraand intracellular 31P NMR pH indicator in isolated organs. Direct NMR evidence of acidic compartments in the ischemic and reperfused rat liver. J Biol Chem, Vol. 276, No 3, pp. 1750-8.

Potapenko, D. I., Bagryanskaya, E. G., Grigoriev, I. A., Maksimov, A. M., Reznikov, V. A., Platonov, V. E., Clanton, T. L. and Khramtsov, V. V. (2005). Quantitative determination of SH groups using 19F NMR spectroscopy and disulfide of 2,3,5,6-tetrafluoro-4mercaptobenzoic acid. Magn Reson Chem, Vol. 43, No 11, pp. 902-9. 
Potapenko, D. I., Foster, M. A., Lurie, D. J., Kirilyuk, I. A., Hutchison, J. M., Grigor'ev, I. A., Bagryanskaya, E. G. and Khramtsov, V. V. (2006). Real-time monitoring of druginduced changes in the stomach acidity of living rats using improved $\mathrm{pH}$-sensitive nitroxides and low-field EPR techniques. J Magn Reson, Vol. 182, No 1, pp. 1-11.

Povich, M. J. (1975). Electron Spin Resonance Oxygen Broadening. J. Phys. Chem., Vol. 79, No, pp. 1106-1109.

Presley, T., Kuppusamy, P., Zweier, J. L. and Ilangovan, G. (2006). Electron paramagnetic resonance oximetry as a quantitative method to measure cellular respiration: a consideration of oxygen diffusion interference. Biophys J, Vol. 91, No 12, pp. 462331.

Quintanilha, A. T. and Mehlhorn, R. J. (1978). pH gradients across thylakoid membranes measured wit a spin-labeled amine. FEBS Lett., Vol. 91, No, pp. 104.

Rabik, C. A. and Dolan, M. E. (2007). Molecular mechanisms of resistance and toxicity associated with platinating agents. Cancer Treat Rev, Vol. 33, No 1, pp. 9-23.

Rosen, G. M., Porasuphatana, S., Tsai, P., Ambulos, N. P., Galtsev, V. E., Ichikawa, K. and Halpern, H. J. (2003). Dendrimeric-Containing Nitronyl Nitroxides as Spin Traps for Nitric Oxide: Synthesis, Kinetic, and Stability Studies. Macromolecules, Vol. 36, No, pp. 1021-1027.

Roshchupkina, G. I., Bobko, A. A., Bratasz, A., Reznikov, V. A., Kuppusamy, P. and Khramtsov, V. V. (2008). In vivo EPR measurement of glutathione in tumor-bearing mice using improved disulfide biradical probe. Free Rad. Biol. Med., Vol. 45, No, pp. 312320.

Saracino, G. A. A., Tedeschi, A., D'Errico, G., Improta, R., Franko, L., Ruzzi, M., Corvaia, C. and Barone, V. (2002). Solvent polarity and $\mathrm{pH}$ effects on the magnetic properties of ionizable nitroxide radicals: a combined computational and experimental study of 2,2,5,5-tetramethyl-3-carboxypyrrolidine and 2,2,6,6-tetramethyl-4-carboxypiperidine nitroxides. J. Phys. Chem. A., Vol. 106, No, pp. 10700-10706.

Sarna, T., Duleba, A., Korytowski, W. and Swartz, H. (1980). Interaction of melanin with oxygen. Arch Biochem Biophys, Vol. 200, No 1, pp. 140-8.

Schafer, F. Q. and Buettner, G. R. (2001). Redox environment of the cell as viewed through the redox state of the glutathione disulfide/glutathione couple. Free Radic Biol Med, Vol. 30, No 11, pp. 1191-212.

Soszynski, M. and Bartosz, G. (1997). Decrease in accessible thiols as an index of oxidative damage to membrane proteins. Free Radic Biol Med, Vol. 23, No 3, pp. 463-9.

Swartz, H. M. (2004). Using EPR to measure a critical but often unmeasured component of oxidative damage: oxygen. Antioxid Redox Signal, Vol. 6, No 3, pp. 677-86.

Swartz, H. M., Khan, N. and Khramtsov, V. V. (2007). Use of electron paramagnetic resonance spectroscopy to evaluate the redox state in vivo. Antioxid Redox Signal, Vol. 9, No 10, pp. 1757-71.

Takeshita, K., Hamada, A. and Utsumi, H. (1999). Mechanisms related to reduction of radical in mouse lung using an L-band ESR spectrometer. Free Radic Biol Med, Vol. 26, No 7-8, pp. 951-60. 
Terpstra, M., Henry, P. G. and Gruetter, R. (2003). Measurement of reduced glutathione (GSH) in human brain using LCModel analysis of difference-edited spectra. Magn Reson Med, Vol. 50, No 1, pp. 19-23.

Tietze, F. (1969). Enzymic method for quantitative determination of nanogram amounts of total and oxidized glutathione: applications to mammalian blood and other tissues. Anal Biochem, Vol. 27, No 3, pp. 502-22.

Ullman, E. F. and Osiecki, J. H. (1970). Stable free radicals. VIII. New imino, amidino and carbomoyl nitroxides. J Org Chem, Vol. 35, No, pp. 3623-3631.

Vaupel, P. (2009). Pathophysiology of Solid Tumors, In: The Impact of Tumor Biology on Cancer Treatment and Multidisciplinary Strategies. M. Molls, P. Vaupel, C. Nieder and M. S. Anscher (Ed.): 51-92, Berlin, Heidelberg, Springer.

Velan, S. S., Spencer, R. G., Zweier, J. L. and Kuppusamy, P. (2000). Electron paramagnetic resonance oxygen mapping (EPROM): direct visualization of oxygen concentration in tissue. Magn Reson Med, Vol. 43, No 6, pp. 804-9.

Voinov, M. A., Polienko, J. F., Schanding, T., Bobko, A. A., Khramtsov, V. V., Gatilov, Y. V., Rybalova, T. V., Smirnov, A. I. and Grigor'ev, I. A. (2005). Synthesis, structure and Xband $(9.5 \mathrm{GHz})$ characterization of the new series of $\mathrm{pH}$-sensitive probes: $\mathrm{N}-\mathrm{N}$ disubstituted 4-amino-2,2,5,5-tetramethyl-3-imidazoline 1 Oxyls. J.Org.Chem., Vol. 70, No, pp. 9702-9711.

Volodarsky, L. B., Reznikov, V. A. and Ovcharenko, V. I. (1994). Synthetic chemistry of stable nitroxides, CRC Press, Boca Raton, Fla.

Weiner, L. M. (1995). Quantitative determination of thiol groups in low and high molecular weight compounds by electron paramagnetic resonance. Methods Enzymol, Vol. 251, No, pp. 87-105.

Willis, J. A. and Schleich, T. (1995). 13C-NMR spectroscopic studies of 2-mercaptoethanolstimulated glutathione synthesis in the intact ocular lens. Biochim Biophys Acta, Vol. 1265, No 1, pp. 1-7.

Woldman, Y., Khramtsov, V. V., Grigor'ev, I. A., Kiriljuk, I. A. and Utepbergenov, D. I. (1994). Spin trapping of nitric oxide by nitronylnitroxides: measurement of the activity of no synthase from rat cerebellum. Biochem Biophys Res Commun, Vol. 202, No 1, pp. 195-203.

Woldman, Y. Y., Semenov, S. V., Bobko, A. A., Kirilyuk, I. A., Polienko, J. F., Voinov, M. A., Bagryanskaya, E. G. and Khramtsov, V. V. (2009). Design of liposome-based pH sensitive nanoSPIN probes: nano-sized particles with incorporated nitroxides. Analyst, Vol. 134, No 5, pp. 904-10.

Yamashita, G. T. and Rabenstein, D. L. (1989). Determination of penicillamine, penicillamine disulfide and penicillamine-glutathione mixed disulfide by high-performance liquid chromatography with electrochemical detection. J Chromatogr, Vol. 491, No 2, pp. 34154 .

Yasui, H., Matsumoto, S., Devasahayam, N., Munasinghe, J. P., Choudhuri, R., Saito, K., Subramanian, S., Mitchell, J. B. and Krishna, M. C. (2010). Low-field magnetic resonance imaging to visualize chronic and cycling hypoxia in tumor-bearing mice. Cancer Res, Vol. 70, No 16, pp. 6427-36. 
Zhu, X., Liu, B., Zhou, S., Chen, Y. R., Deng, Y., Zweier, J. L. and He, G. (2007). Ischemic preconditioning prevents in vivo hyperoxygenation in postischemic myocardium with preservation of mitochondrial oxygen consumption. Am J Physiol Heart Circ Physiol, Vol. 293, No 3, pp. H1442-50.

Zweier, J. L. and Kuppusamy, P. (1988). Electron paramagnetic resonance measurements of free radicals in the intact beating heart: a technique for detection and characterization of free radicals in whole biological tissues. Proc Natl Acad Sci U S A, Vol. 85, No 15, pp. 5703-7. 